\title{
Computational Methodology to Study Heterogeneities in Petroleum Reservoirs
}

\author{
J. T. Cevolani, SPE, Federal University of Espirito Santo (UFES) \\ A. E. Mostafa, University of Calgary \\ E. A. Vital Brazil, University of Calgary \\ L. Costa de Oliveira, Federal University of Espirito Santo (UFES) \\ L. Goliatt da Fonseca, Federal University of Juiz de Fora (UFJF) \\ M. Costa Sousa, University of Calgary
}

\begin{abstract}
Characterization of hydrocarbon reservoirs is strategically important to define the productivity of oil and/or gas fields. It involves many challenges such as appropriate identification, classification and interpretation of diagenetic processes that directly affect the quality of the reservoirs. Proper studies demand integration and analysis of very large amounts of data, usually presenting high-dimensional feature spaces. Current methods have many manual steps leading to a limited exploration of the data. These challenges are being intensified due to the need of knowledge and time dedication from experts. We developed a novel methodology that combines established techniques, such as Principle Component Analysis (PCA), clustering methods, parallel coordinates and scatter plots, with features such as dynamic (magic) lenses - filter and shadow lenses -, axes reordering and color maps, to automatically perform reservoir characterization in order to assist the identification, validation and interpretation of petrofacies. Petrofacies is a set of petrographic characteristics of microscopic order which allow the analyst to understand the diagenetic processes, aiding in the evaluation of the potential for hydrocarbon storage in the reservoir. We have applied our methodology on several databases from different sedimentary basins - Espirito Santo and Parana basins (Brazil), Talara Basin (Peru) and Niger Delta Basin (Nigeria). We conclude that our method allows the analyst to gain insights about the entire database in a manner that is faster than the analysis using manual methods. It also allows validation of the results because it is a powerful tool that can qualitatively and quantitatively support the analyst in the identification, interpretation and validation of petrofacies. This new methodology can optimize data analysis of similar databases, accelerating the analysis and reducing the committed work by the experts.
\end{abstract}

\section{Introduction}

Prediction models, the mapping of distribution of heterogeneities, and reservoir quality are very important for performing tasks such as exploration and production optimization of hydrocarbon fields. Normally all steps for the geological sampling process, data generation and their interpretation are carried out by manual methods. These are time consuming methods and take a long time to complete due to the very large amount of data that the geologist has; the large volume of information is cumbersome to use.

Heterogeneities control the amount of hydrocarbon that may be in a reservoir and the recovery efficiency. Therefore, for a good characterization, it is necessary to describe the lithologic structure and the distribution of diagenetic changes in the reservoir (Mukerji, T. et al, 2001). This analysis can be done in a multi-scalar way, which is now one of the primary methods used to evaluate the quality of reservoirs (Küchel and Holz, 2002). It includes 5 heterogeneity levels: from heterogeneities in depositional sequences (level 1) to heterogeneities of the grain, cement and pores (level 5), which have a higher resolution degree. The analysis for this last level is carried through sedimentary petrography techniques that have the ability to meaningfully characterize voids that are capable of storing oil, gas and/or water. In this work we use an analysis based on Level 5: grain, cement and pores.

With this process in mind, as the amount of data increases, it becomes necessary to change from pure manual steps to automatic analysis through computational tools that facilitate extracting knowledge from the data. At the same time, it is important to provide tools to allow interactive data manipulation and interpretation. The overall methodology and tools should support both automatic and interactive techniques. In this context, the clustering and visualization techniques are interesting tools to assist in the identification of sedimentary petrofacies. These techniques are often used to search for new and non-trivial information in huge amounts of data. Usually, better results are achieved with the balance between the expert knowledge and the computational methods capacity.

The application of multivariate techniques on compositional data for geology started to be more used after the definition of the sample space and the mathematical treatment of the data inside this space, as reported in the monograph of Aitchison (1986). Aitchison defines compositional data as those data which contain only relative information. They are part of a larger whole. They are also called 'closed data' because in most cases they sum to a constant 1 , or equivalently 100 percent. Aitchison also developed CoDA, a microcomputer package for the statistical analysis of compositional data that contains all the applications developed such as subcompostions amalgamations, partitions and perturbations, aiming to allow the user to explore their own compositional databases quickly and simply. The following brief history, based on Aitchison's methodology, can be found in Buccianti et al (2006).

Thió-Henestrosa and Martín-Fernández (2001) wrote the CoDAPack freeware software and implemented the basic methods of analysis of compositional data based on log-ratios, following the methodology introduced in Aitchison (1986). 
Some attempts to analyze compositional databases were written in R (R Development Core Team). Reynolds and Bilheimer (2002) wrote Basic Composition Data Analysis functions for S+/R comprising basic operations, transformations, estimators and plots. In 2003, Bren and Batagelj began to develop a library MixeR of functions in $\mathrm{R}$ to support the analysis of compositional data. The routines were provided for operations on compositions including all the ones presented in the Aitchison's theory. Compared with the previous methods, new features were added such as centering of the data and log-ratio transformations. The latter, according to Aitchison (1986), is an important feature because it transforms the compositions into real vectors that are amenable to standard multivariate analysis. These are inappropriate if applied over the raw data. In 2005, Halvorsen reported his work on coding some compositional routines in R (operations on compositions, additive logratio (alr) and centered logratio (clr) transformations - defined by Aitchison (1986)). In the same year, van der Boogaart and TolosanaDelgado published a 'compositions' package for R. This package supports four different multivariate scales represented by four different classes and the user determines the selection depending on the type of database that needs to be analyzed.

For automatic identification of lithofacies, the techniques for recognition of supervised and unsupervised patterns are being proposed to solve its problems. The majority of the approaches use workflows which integrate methods for dimensionality reduction such as Principle Component Analysis (PCA, Lee and Datta-Gupta, 1999), partition and hierarchical clustering methods, as well as classification techniques such as Discriminant Analysis (Bosch et al, 2002), Nearest Neighbor Rule and Neural Network (Al-Anazi and Gates 2010; Ma 2011; Dubois et al, 2006).

With all this in mind, we developed a new method that is based on clustering techniques to allow identification, classification, validation and interpretation of petrofacies. This method contains statistical and visual analytic techniques such as multidimensional scaling and cluster analysis, to allow the geologist to understand the behavior of the petrofacies and provide insights about the whole database. With this method, the user can also visually analyze, correlate and extract the main data trends through the use of parallel coordinates and scatter plots while allowing outliers' detection and removal.

Next, we describe the materials and our methodology, and then we review the statistical coding in $\mathrm{R}$ and the clustering process. After that, we highlight the usage of parallel coordinates for visually analyzing the data. Finally, we conclude by discussing the results and some future work that we intend for improving this work.

\section{Materials and Method}

The databases used in this work are compositional data from four different sedimentary basins - Parana and Espírito Santo basins in Brazil, Niger Delta Basin in Nigeria and Talara Basin in Peru.

The Espírito Santo Basin is one of the passive margin basins, originated from the continental separation of South American and African plates, with peculiar tectonic, structural and sedimentary characteristics. Its sedimentary package records the evolution of the South America eastern margin influenced by distinct tectonic periods. According to Asmus and Porto (1980), the rupture of the crust and the opening of the South Atlantic led to the formation of rift basins in the Cretaceous period, a process accompanied by intense basaltic magma of the Paraná, Campos and Santos basins.

The data from the Espírito Santo Basin treated in this work are related to fluvial and estuarine sandstones of Mucuri Member, of the Mariricu Formation (a pre-salt formation) and were obtained from the work of Silva (1991). These are the main reservoirs of oil in the onshore portion of the Espírito Santo Basin. These reservoirs show high heterogeneity produced by the superposition of varied and intense diagenetic processes on the geometric and textural complexity generated during the deposition. The high heterogeneity challenges production procedures and limits the efficiency of oil recovery from Mucuri's reservoirs.

On the other hand, the Paraná Basin is an intracratonic basin entirely developed on continental crust and filled with sedimentary and volcanic rocks. This basin has an area greater than $1,400,000 \mathrm{~km}^{2}$, with portions located in Brazil, Argentina, Paraguay and northern Uruguay. According to Zalán et al (1990), it has an elongated shape in NNE-SSW direction, with an average width of $900 \mathrm{~km}$. It is characterized by Paleozoic-Mesozoic sedimentation, with a stratigraphic record aged between Neo-Ordovician and the Neo-Cretaceous.

The sandstones of the Paraná Basin related to this work are from its Devonian Section, registered in the southern region of Brazil (Tibagi and Ponta Grossa). Such sandstones generally have granulometry ranging from fine to very fine. The rounding of the grains is generally sub-angular to sub-rounded (Oliveira, 2009). The computational data, as well as tables of quantitative petrographic constituents of these sandstones are in accordance with Cevolani et al (2011) and will not be discussed in this paper.

The Niger Delta Basin consists of Cenozoic formations and covers approximately 260,000 $\mathrm{km}^{2}$ (Chukwu, 1991). The delta complex is deformed by well-developed growth faults and large-scale mud diapirs, and its growth is closely related to the development of the diapirs. The sediments are partly marine and partly fluvial in origin, and are separated in three identified formations: Benin, Agbada and Akata. The first formation originated in the Oligocene to Recent and contains more than $90 \%$ of sand with a few shale intercalations. The sandstones are coarse- to fine-grained with grains sub-angular to wellround. The second formation consists mainly of alternations of sands, sandstones and siltstones, the sandy parts of which constitute the main hydrocarbon reservoirs in the delta oilfields. In general, the reservoirs show considerable lateral heterogeneity, which is a major characteristic of many Niger Delta oilfields (Chukwu, 1991). The shales are important because they act as reservoirs seals. The third and last formation is composed of marine shales, but also contains sand and 
silty beds. The shales are very rich in planktonic foraminifera which make the Akata Formation the main source rock for oil and gas.

Lastly, the Talara Basin in Peru is substantially controlled by Late Cretaceous - early Tertiary tectonic activities that involve Paleozoic and Mesozoic strata resulting from Paleogene tectonic activity (Higley, 2004). The creation of the Talara Basin province in Paleocene and Eocene time resulted from both subduction of the Nazca Plate under the South American Plate and depositional events that were related to transtensional and extensional tectonics. It is filled with clastic sediments from the continent combined with shallow- and deep-water marine limestones. All the oils from this basin were from source rocks of similar origin, such as shales deposited in a marine setting. The reservoirs are mainly sandstones from several formations such as Amotape, Mesa and Balcones Formations.

The three databases (Talara, Niger Delta and Espirito Santo Basins) have a total of 30 wells and 280 thin-sections. The columns of the databases correspond to a single thin-section from the cored wellbores and the rows correspond to attributes that were observed in the thin-sections through microscopic analysis. Each line sums $100 \%$ and contains just non-negative values. An example of the layout of the database can be seen in Table 1. In this table, the name of the samples is composed of the name of the well together with a number, which represents the sample according with the depth where the thin-section was collected. For each well, the bigger this number, the deeper the sample is.

\begin{tabular}{|c|c|c|c|c|c|c|c|}
\hline \multicolumn{8}{|c|}{ TABLE 1 - EXAMPLE FOR THE LAYOUT OF THE DATABASE } \\
\hline$\underline{\text { Samples/Attributes }}$ & $\underline{\text { Well 1-1 }}$ & $\underline{\text { Well 1-2 }}$ & $\underline{\text { Well } 1-3}$ & $\underline{\text { Well 1-4 }}$ & $\underline{\text { Well 2-1 }}$ & $\underline{\text { Well 2-2 }}$ & $\underline{\text { Well 2-3 }}$ \\
\hline Depth (m) & 1232.7 & 1233.7 & 1260.1 & 1288.9 & 1346.7 & 1347.8 & 1350.4 \\
\hline Quartz monocrystalline & 40 & 30.6 & 35.2 & 32.8 & 37 & 33 & 36.4 \\
\hline Quartz polycrystalline & 13.6 & 17.5 & 12.5 & 19.8 & 15.6 & 14.6 & 15.8 \\
\hline K-feldspar & 1.5 & 2.1 & 1.8 & 0 & 0.8 & 1.2 & 2.8 \\
\hline Lithics fragments & 1.7 & 3.5 & 7.8 & 0 & 0 & 6.8 & 8.3 \\
\hline $\begin{array}{l}\text { Pyrite - Coarsely- } \\
\text { crystalline }\end{array}$ & 0 & 0 & 0 & 0 & 0 & 1.4 & 0 \\
\hline Pyrite - Framboid & 2.1 & 9.6 & 9.1 & 9.4 & 18.8 & 5.6 & 10.9 \\
\hline Smectite - Microcrystalline & 0 & 0 & 0 & 0 & 0 & 0 & 0 \\
\hline Smectite - Rim & 0 & 0 & 0 & 0 & 0 & 6.4 & 8.8 \\
\hline Smectite - Splays & 8.7 & 0 & 0 & 6.2 & 0.8 & 8.2 & 3.5 \\
\hline Kaulinite & 0 & 0 & 0 & 0 & 0 & 0 & 0 \\
\hline Chlorite & 6.8 & 28.4 & 32 & 31.8 & 8.4 & 0 & 0 \\
\hline Calcite & 0 & 0 & 0 & 0 & 0 & 0 & 0 \\
\hline Intergranular porosity & 22.6 & 8.3 & 0 & 0 & 16.2 & 17.6 & 9.9 \\
\hline Intragranular porosity & 3 & 0 & 1.6 & 0 & 2.4 & 5.2 & 3.6 \\
\hline
\end{tabular}

To read this file in our system, we developed a code in R language. We chose $\mathrm{R}$ for three main reasons: (1) it is an opensource program making it widely available, (2) of the simplicity to develop very intricate and complicated analysis without knowing the details of computing systems, and (3) it contains a number of built-in mechanisms for organizing data, running calculations on the information and creating graphical representations of databases.

The code performs the clustering analysis by applying two different built-in clustering methods: Partitioning Around Medoids (PAM, partitioning method) and Agglomerative Nesting (AGNES, hierarchical method; Kaufman and Rousseeuw, 2005). Using clustering analysis it is possible to put together samples where those in the same group are more similar to each other compared to the samples that are in other groups, according to a dissimilarity measure. These groups are what we call the possible petrofacies of the database.

For the PAM method we applied Euclidean distance as the dissimilarity measure. The best value for the number of clusters was found by applying silhouette analysis over the results. This value is the one which maximizes the Silhouette Coefficient (SC). The Principle Component Analysis (PCA) was applied on the output from PAM in order to visualize the results in 2-dimensional space.

Next, we applied AGNES to the original database, using the group average method (also called unweighted pair-group average method) to calculate the dissimilarities between clusters. The strength of the clustering structure obtained by the group average linkage was defined by calculating the agglomerative coefficient (AC) for the output plots (banner and dendrogram).

This entire process was performed for wells that contain three samples or more, whose characteristics are identified by the code itself. We also used some packages in R to be able to apply some specific calculations and plot the results. 
PAM gives an exact number of clusters for each well and based on the silhouette analysis, the output from the PAM clustering was automatically added to the original table of the database. An output file was created for this combination. The Table 2 exemplifies the layout for this file. It contains one more line which represents the cluster's references. These references are related to a specific well, that means the same numbers for samples for the same well represent the same cluster; the same numbers for samples from different wells represent different clusters.

\begin{tabular}{|c|c|c|c|c|c|c|c|}
\hline \multicolumn{8}{|c|}{ TABLE 2 - EXAMPLE FOR THE OUTPUT FROM THE CODE } \\
\hline$\underline{\text { Samples/Attributes }}$ & $\underline{\text { Well 1-1 }}$ & $\underline{\text { Well 1-2 }}$ & $\underline{\text { Well } 1-3}$ & $\underline{\text { Well } 1-4}$ & $\underline{\text { Well 2-1 }}$ & Well 2-2 & $\underline{\text { Well 2-3 }}$ \\
\hline Depth (m) & 1232.7 & 1233.7 & 1260.1 & 1288.9 & 1346.7 & 1347.8 & 1350.4 \\
\hline Quartz monocrystalline & 40 & 30.6 & 35.2 & 32.8 & 37 & 33 & 36.4 \\
\hline Quartz polycrystalline & 13.6 & 17.5 & 12.5 & 19.8 & 15.6 & 14.6 & 15.8 \\
\hline K-feldspar & 1.5 & 2.1 & 1.8 & 0 & 0.8 & 1.2 & 2.8 \\
\hline Lithics fragments & 1.7 & 3.5 & 7.8 & 0 & 0 & 6.8 & 8.3 \\
\hline $\begin{array}{l}\text { Pyrite - Coarsely- } \\
\text { crystalline }\end{array}$ & 0 & 0 & 0 & 0 & 0 & 1.4 & 0 \\
\hline Pyrite - Framboid & 2.1 & 9.6 & 9.1 & 9.4 & 18.8 & 5.6 & 10.9 \\
\hline Smectite - Microcrystalline & 0 & 0 & 0 & 0 & 0 & 0 & 0 \\
\hline Smectite - Rim & 0 & 0 & 0 & 0 & 0 & 6.4 & 8.8 \\
\hline Smectite - Splays & 8.7 & 0 & 0 & 6.2 & 0.8 & 8.2 & 3.5 \\
\hline Kaulinite & 0 & 0 & 0 & 0 & 0 & 0 & 0 \\
\hline Chlorite & 6.8 & 28.4 & 32 & 31.8 & 8.4 & 0 & 0 \\
\hline Calcite & 0 & 0 & 0 & 0 & 0 & 0 & 0 \\
\hline Intergranular porosity & 22.6 & 8.3 & 0 & 0 & 16.2 & 17.6 & 9.9 \\
\hline Intragranular porosity & 3 & 0 & 1.6 & 0 & 2.4 & 5.2 & 3.6 \\
\hline CLUSTER & 1 & 2 & 2 & 2 & 1 & 2 & 1 \\
\hline
\end{tabular}

Table 2 is the input for the second step of the methodology, the interactive tool. This tool combines parallel coordinates with features such as dynamic (magic) lenses (filter and shadow), axes reordering and color maps, and scatter plots. We also added a statistical analysis over the data in the parallel coordinates, based on variance or quartile, which is a feature that can be chosen by the user to help in the qualitative analysis of the clusters.

\section{Results and Discussion}

In this section, we discuss the results of our methodology. We start by discussing the creation of the clusters (possible petrofacies) using our implementation through the $\mathrm{R}$ language. Then, we show how the analyst can interact and visually analyze (and validate) the clusters using our interactive tool and its parallel coordinates' implementation.

\section{The Code in $R$ and Clustering Process}

The code developed in the R language applies the PAM and PCA over the data to read the databases from the basins, to perform the $2 \mathrm{D}$ visualization, and to create the clusters to analyze the similarities between the samples. PAM performs a partition of the samples according to the number of clusters specified by the user. We chose this method because, according to Kaufmman and Rousseeuw (2005), it is more robust than the error sum of squares employed in most methods, such as Kmeans, which is the most widely applied nonhierarchical clustering method. Furthermore, it allows a good characterization of all clusters that are not too elongated and makes it possible to isolate outliers in most situations. The results for the algorithm in PAM do not depend on the order of the thin-sections in the input file, unlike in many other methods. As a validity criterion we have applied silhouette analysis. The Silhouette Coefficient (SC) is a simple and powerful criterion when compared with other criteria (Vendramin et al, 2010). The SC is a useful measure of the amount of clustering structure that has been discovered by the classification algorithm. For each cluster, SC ranges from -1 to 1: the values of silhouette that are closer to 1 mean an improved arrangement of the clusters compared to a smaller SC, when SC=-1 it indicates a misclassified sample. The SC criterion consists of an average of the SC values over the entire database.

The analysis of the SC's values allows the user to create a table as Table 3 containing the number of clusters (possible petrofacies) for the wells from each basin. Table 3 shows the number of clusters found in each well for Talara, Niger Delta and Espírito Santo Basins. All the values for the Silhouette Coefficient in the analysis of the clusters can be found in the Appendix A. 


\begin{tabular}{|c|c|c|c|c|c|c|c|c|c|c|}
\hline \multirow{4}{*}{ \# Clusters } & \multicolumn{3}{|c|}{$\underline{\text { Talara Basin }}$} & & \multicolumn{6}{|c|}{$\underline{\text { Niger Delta Basin }}$} \\
\hline & Well 1 & Well 2 & Well 3 & & Well 5 & Well 6 & Well 7 & Well 8 & Well 9 & Well 10 \\
\hline & 3 & 5 & 3 & & 5 & 2 & 2 & 2 & 4 & 3 \\
\hline & \multicolumn{10}{|c|}{ Espírito Santo Basin } \\
\hline \multirow{3}{*}{ \# Clusters } & Well 11 & Well 13 & Well 14 & Well 15 & Well 16 & Well 17 & Well 18 & Well 19 & Well 20 & Well 21 \\
\hline & 2 & 3 & 3 & 2 & 2 & 2 & 2 & 4 & 5 & 2 \\
\hline & Well 22 & Well 24 & Well 25 & Well 26 & Well 30 & & & & & \\
\hline \# Clusters & 2 & 3 & 2 & 2 & 2 & & & & & \\
\hline
\end{tabular}

We applied PCA, to allow plotting the data for the 2-first principal components (2D plot), to visualize the sample arrangements and the clusters that were found. Figure 1 shows the results from the PCA for one well from each basin. For Well 2 the method found 5 clusters. The clusters in dark blue, light blue and red seem to be well defined and the remaining (green and pink) have an overlap for some of the samples. For Well 10 the method found 3 clusters that seem to be well structured. For Well 20 the method found 5 clusters, in which the green, pink and dark blue ones seem to have a good structure, while the clusters in red and light blue present a spread structure. The results for the other wells can be found in Appendix B. To demonstrate the process we will present the analysis for Well No.2, 10 and 20 as the process is the same for every well.

In this work, the goal is to find the correct number of petrofacies or, at least, to try to give to the analyst an idea about the different petrofacies that can be present in the database. To achieve this, the most applicable technique is the partitioning one, due to the fact that the PAM method produces a final number of clusters (petrofacies) according to the silhouette analysis. We applied Agglomerative Nesting to identify those samples that were similar to each other and from this, determine if the samples present in the clusters classified by PAM make sense to be combined. AGNES is indeed much faster than partitioning into a fixed number of clusters. Agglomerative procedures do have a defect: a 'wrong' fusion can never be repaired in the subsequent steps, whereas for a fixed number of clusters, a program like PAM will try to find a near optimal solution. The choice between a hierarchical and a nonhierarchical method depends mainly on the purpose of the investigation (Kaufmman and Rousseeuw, 2005).

AGNES performs a hierarchical analysis, first considering each sample as a cluster and then proceeds by successive fusions, according to the similarity between the samples, until a single cluster is obtained containing all samples. As mentioned before, the strength of the formed structure is defined by the agglomerative coefficient (AC). However, the AC tends to become larger when the number of samples increases, so it should not be used to compare databases of very different sizes (Kaufmman and Rousseeuw, 2005). The results from the application of this method can be found in Figure 2 for the same three wells showed before and the remaining can be found in Appendix C.

Figures $2 \mathrm{a}, 2 \mathrm{c}$ and $2 \mathrm{e}$ are banners that show the hierarchical structure found by AGNES. A banner is read from left to right. The white space at height 0 indicates the original state where all the objects are separate entities. When the first red bar starts it means that the two objects (samples) were more similar to each other and were joined. The height for this linking indicates the level where it happened. The other bars follow the same logic but the linking for them happens in higher levels. The highest height is the last level. After this point, all the objects are together in a single cluster.

Figures $2 b, 2 d$ and $2 f$ exhibit another way to analyze the same results - the dendrogram. The dendrogram is read from bottom to top. In the height 0 all samples are alone, each of them corresponding to a single cluster. Moving up in the Height axis, a red dot indicates the first linkage between two objects. These are the same two objects found in the first red bar in the banner, since the two plots are representing the same results. The name of the objects can be found in the red color at the end of each branch in the height 0 . Each red dot specifies a connection between the objects and also between the clusters. In the top of the dendrogram there is a single red dot that links all the branches, and any further height there remains a single cluster containing all the samples.

Comparing the results from the two methods it is possible to see that, for Well 2 (Figures 1, 2a and $2 \mathrm{~b}$ ) only one sample is not in the same group in both PAM and AGNES. The sample Well_02-20 appears in the cluster green with the samples Well_02-3, Well_02-4, Well_02-5, Well_02-6, Well_02-7, Well_02-9, Well_02-10, Well_02-11, Well_02-12, Well_02-13 and Well_02-14. It appears in a single branch in the AGNES method, which can be interpreted to mean it is not as similar to the samples as PAM meant. The other clusters are the same for both methods. The cluster in red contains the samples Well_02-1 and Well_02-2. The cluster in dark blue contains the samples Well_02-8 and Well_02-24. The cluster in light blue contains the samples Well_02-15, Well_02-16, Well_02-21, Well_02-22, Well_02-23 and Well_02-25. Lastly, the cluster in pink contains the samples Well_02-17, Well_02-18, Well_02-19 and Well_02-26. For Well 10 (Figures 1, 2c and 2d), all samples are in the same clusters for the PAM results and the AGNES results. This confirms the well-defined structure 
visualized in the PCA plots for the PAM method. The red cluster contains the samples Well_10-1 and Well_10-6. The green cluster contains the samples Well_10-2, Well_10-3, Well_10-4, Well_10-13, Well_10-14 and Well_10-15. The dark blue cluster contains the samples Well_10-5, Well_10-7, Well_10-8, Well_10-9, Well_10-10, Well_10-11, Well_10-12, Well_1016 and Well_10-17.
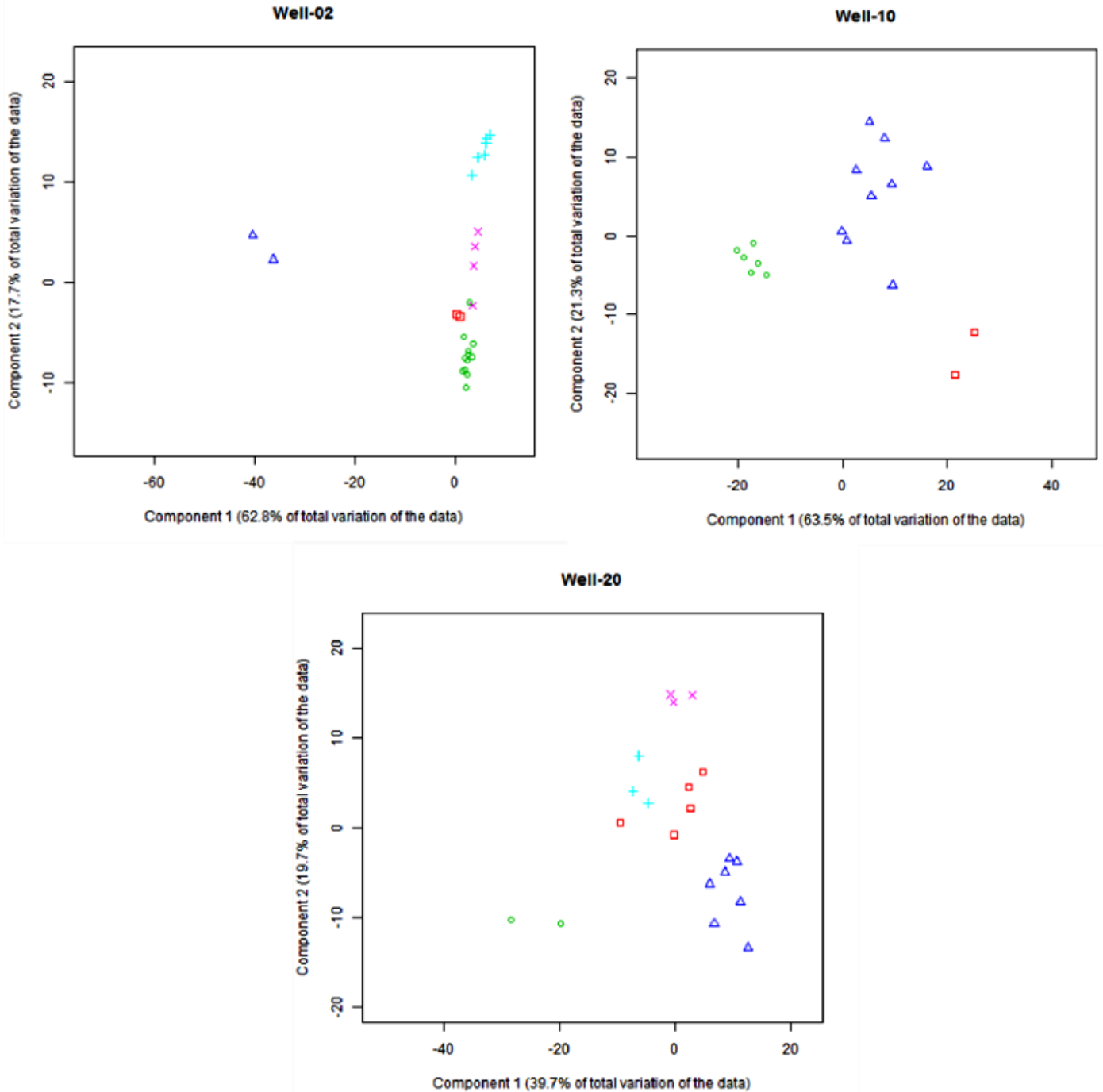

Fig. 1 - PCA plot showing the results of PAM for Well 2 - Talara Basin, Well 10 - Niger Delta Basin and Well 20 - Espírito Santo Basin. Each color and shape represents one cluster. The axes represent 2 first principal components and the percentage of the data they convey.

Last but not least, the classification for Well 20 (Figures 1, 2e and 2f) appears a bit cluttered. Both methods - PAM and AGNES - show two well-defined clusters: the pink (samples Well_20-17, Well_20-18 and Well_20_19) and the green (samples Well_20-2 and Well_20-3) ones. The cluster in dark blue, represented by triangles, contains the samples Well_20-7, Well_20-8, Well_20-9, Well_20-10, Well_20-11, Well_20-12 and Well_20-16. It seems to be well clustered in the PAM method, but in the AGNES' results it contains the sample Well_20-6, which is present in the red cluster in the PAM results. The cluster in light blue (plus symbol) contains the samples Well_20-13, Well_20-14 and Well_20-15. In the AGNES results the sample Well_20-13 is not in the same cluster as the other two samples, but it has a branch connected to them and other three samples (Well_20-17, Well_20-18 and Well_20-19 - the pink cluster). This indicates some similarity among them. The last cluster in the PAM results for Well 20 is the red cluster. It is possible to interpret that this cluster is not well defined by analyzing the distance between the samples in the plot for PAM's results (Figure 1). The red cluster presents the samples Well_20-1, Well_20-4, Well_20-5, Well_20-6 and Well 20-20 far from each other when compared with the distances between the samples in the well-defined pink and green clusters. This can be seen also in the AGNES results: the sample Well_20-6 is in the dark blue cluster and Well_20-1 and 20-20 are considered not as similar to the others. They appear in singles branches in the dendrogram and are only connected to the entire structure at a higher level. 
A wellor

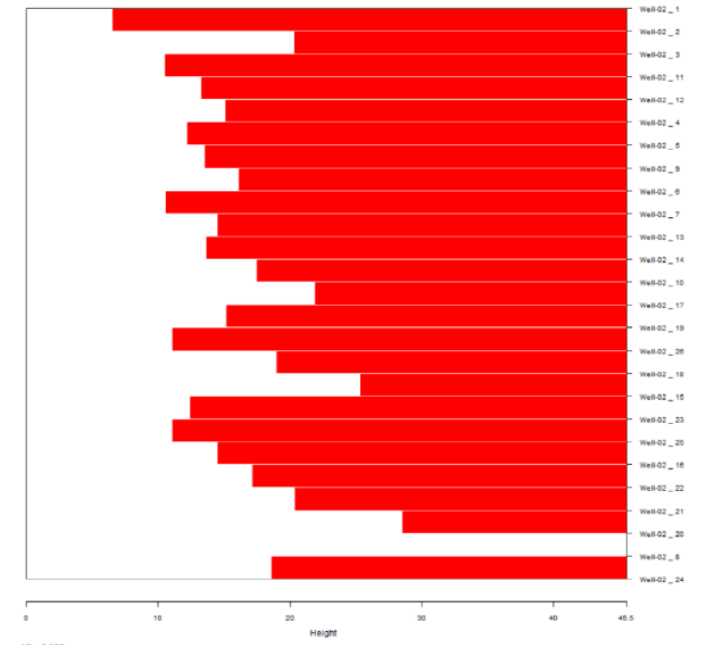

C well-10

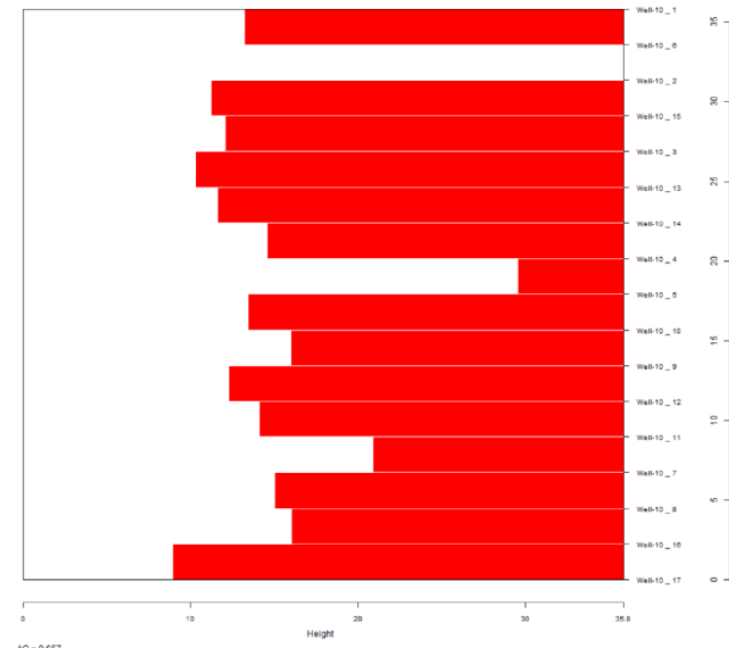

E well-20

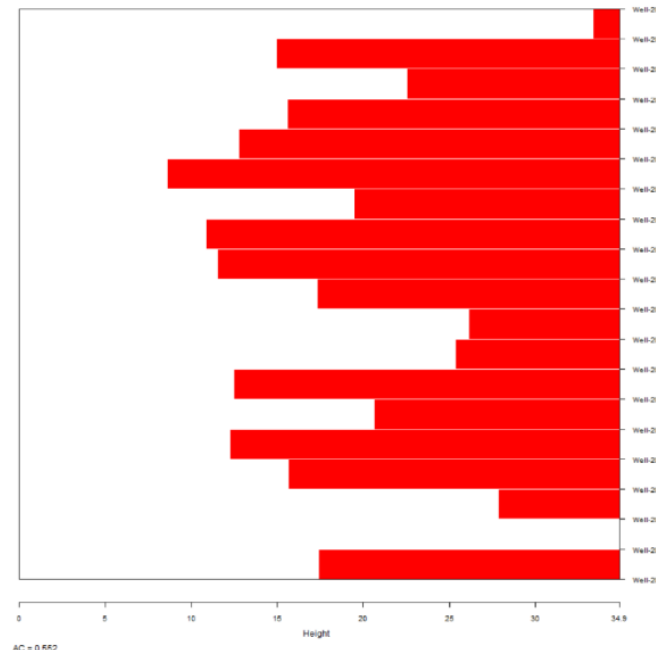

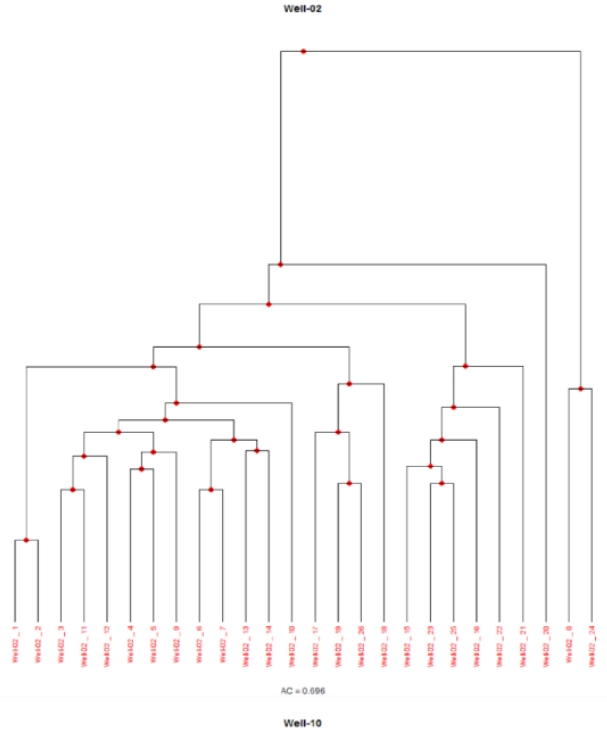

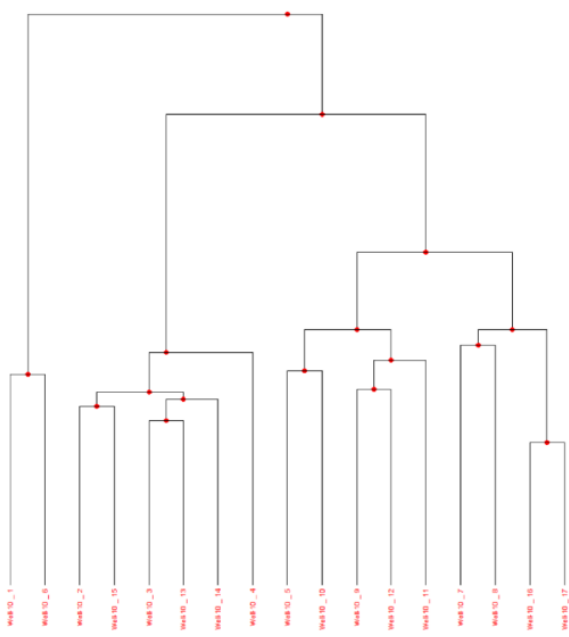

${ }_{4 C=0.55}$

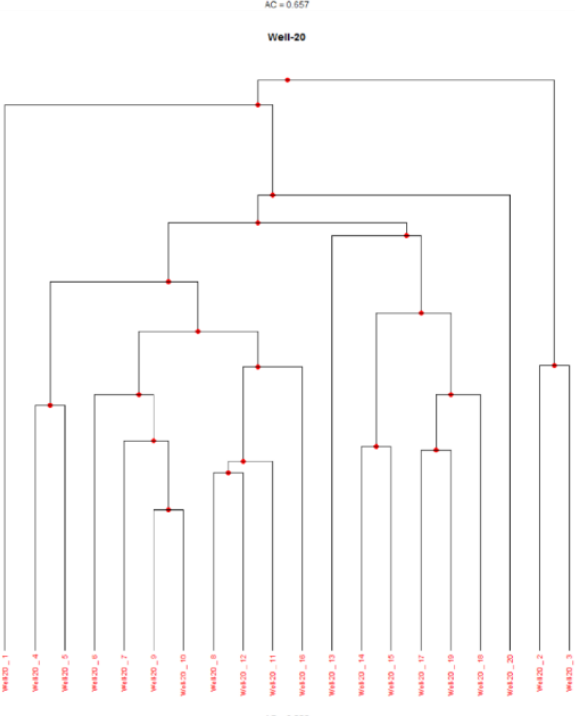

Fig. $2-A, C$ and $E$ are banner plots; and $B, D$ and $F$ are dendrograms plots for Wells $2(A C=0.696), 10(A C=0.657)$ and $20(\mathrm{AC}=0.552)$, respectively.

By analyzing only the AC for these wells, the structures that were found are relatively strong because they have AC higher than 0.5. When the SC or AC is very small, the corresponding method did not find clusters, or rather, the data consists of one big cluster. On the other hand, when the value of the coefficient is close to 1 it can be interpreted to mean that a very 
clear clustering structure has been identified, even if the cluster which was found is not the 'right' one. As a result, the use of the coefficient as a quality quantifier needs to be accompanied by a look at the graphical output and an analysis of the clusters that have been obtained. This task is better completed by using the second part of our methodology.

\section{Parallel coordinates}

The results from the first part of our methodology (the R code) allow the analyst to gain insights about the behavior of the samples, but do not facilitate deeper interpretations as a quantitative analysis of each cluster (petrofacies). The second part of our methodology (the interactive tool) enables the analyst to interactively see how the clusters are formed and at the same time the analyst can check the values of each mineral for each specific sample, allowing the quantitative analysis.

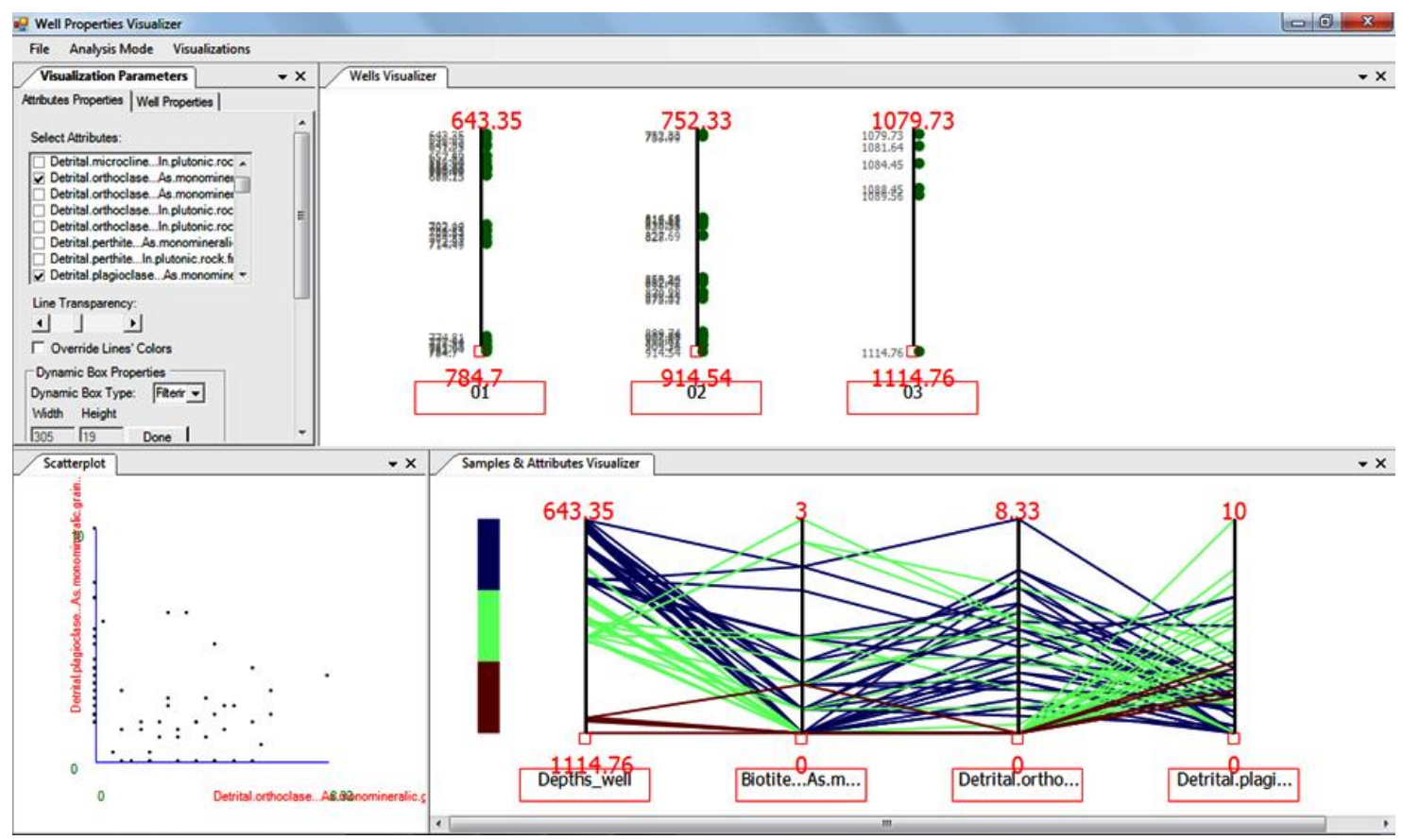

Fig. 3 - Interface of the interactive part of the tool.

Parallel Coordinates is a technique dating from 1985 and aims at displaying multidimensional data in 2D. This permits the user to get a better overview insight of the data (Inselberg, 1985). In this technique, each dimension (in our case, each property counted in the microscopic analysis) is represented as a vertical axis and they are organized as uniformly spaced lines. Each sample of the database is mapped to a polyline that traverses across all axes crossing each axis at a position proportional to its value for that dimension. The size of the database is a limitation to the use of parallel coordinates. If the amount of samples increases, the visualization becomes cluttered and the analysis is difficult. To improve the interaction and exploration of the database by the analyst, and to facilitate a better understanding of the composition of the cluster and the samples, some features were integrated with parallel coordinates (dynamic [magic] lenses both filter and shadow lenses, axes reordering, scatter plot and color maps).

Figures 3 and 4 show the display for the first analysis mode of the methodology. It allows the user to have a general understanding about the data being analyzed. In Figure 3, the menu in the gray background is where the attributes can be chosen as for the parallel coordinates as for the scatter plot. The parallel coordinates in the upper right represent all the samples present in each well of the basin and are positioned according to the depth where they were collected in the core. The scatter plot in the lower left allows the correlation of two attributes chosen by the user. The information of the attributes can be visualized for a single well or for all the wells presented in the data set, according to the intention of the user. This feature can be visualized in Figure 4. Lower right in Figure 3 is where the analyst can correlate all the attributes in a single well or for the number of wells that the analyst selects. Each well is represented by one color and each line represents one sample/thin-section. Each parallel coordinate represents an attribute and contains the range of values for this attribute present in the database. Each line (sample) will cross one coordinate in the point representing the value of this attribute for this specific sample. This is the value that the analyst determined by the analysis of the thin-section in the microscopic.

When the mouse pointer is on a sample or on a point in the axes, the tool exhibits the values of the two closest coordinates/attributes of the sample(s) that are being selected by the pointer (Figure 4). This feature allows the quantitative analysis of the data removing the need of the analyst to go back to the database file. 


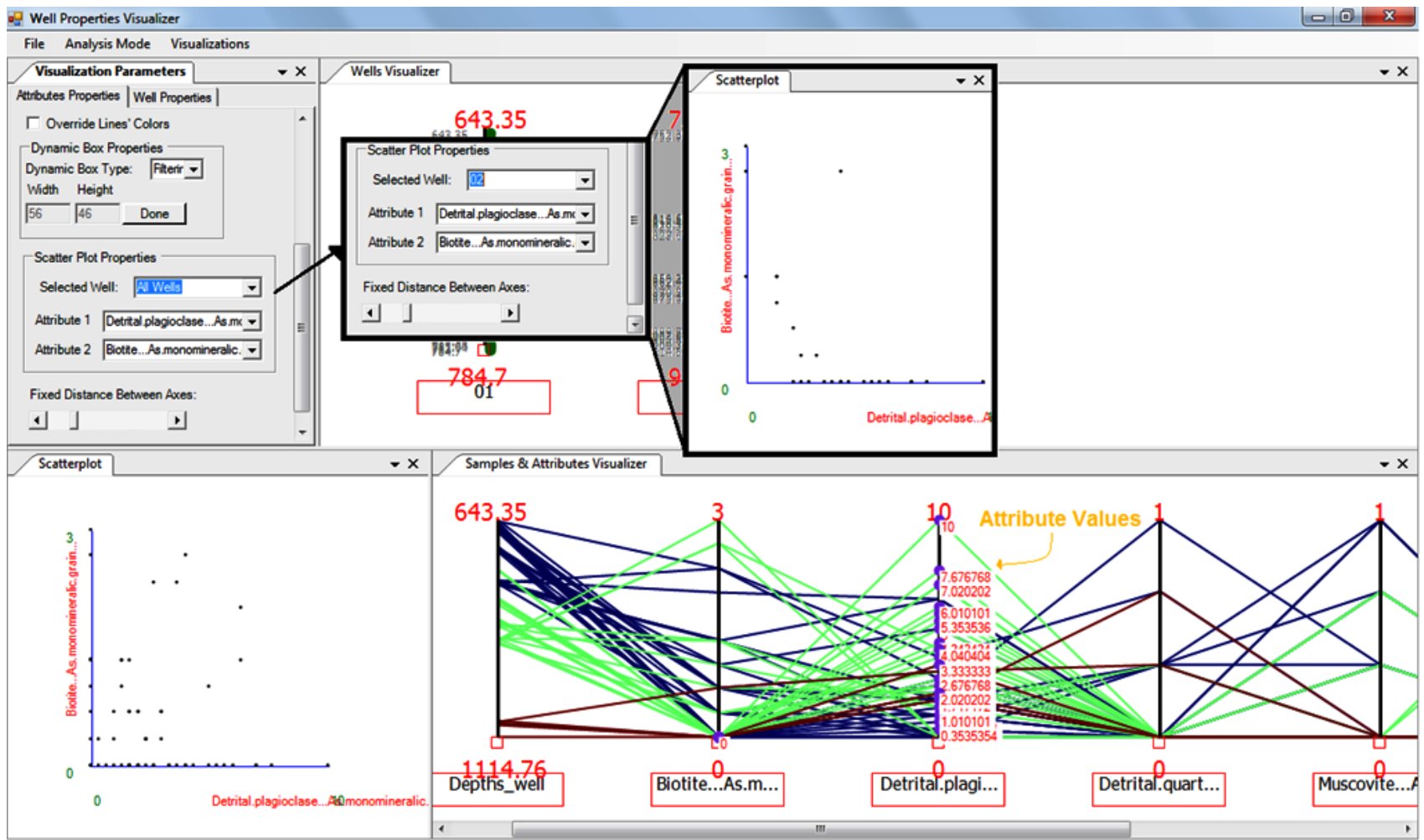

Fig. 4 - Scatter plot selection for all wells of the basin or for a specific one; and attribute values for the two attributes which are being analyzed in the scatter plot.

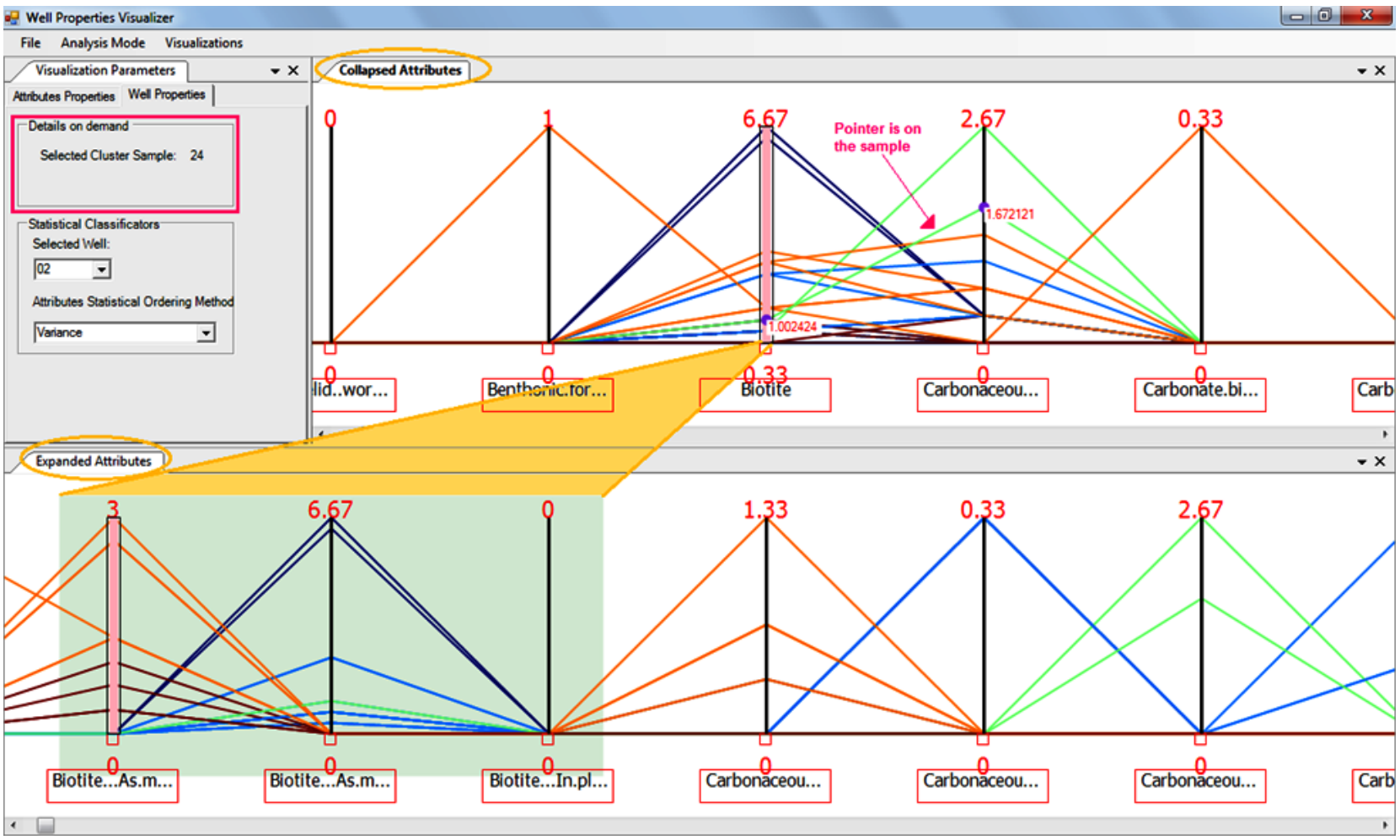

Fig. 5 - Display of the second Analysis Mode of the tool. Features such as shadow lenses (yellow and green highlights) and samples specification (pink highlight and arrow) can be visualized in this figure.

By changing the Analysis Mode in the upper menu, the display shifts and the analysis becomes more detailed. The new display, exhibited in Figure 5, contains two parallel coordinates. In this mode the data is displayed for the one well selected by the user. The colors represent the clusters (petrofacies) that were obtained from the PAM method. Hence, samples with the 
same color have similar characteristics and theoretically represent the same petrofacies for that well. As some databases are very detailed, one single mineral can have several ways to be present in the thin-section and be described, based on the level of detail available. This characteristic is important, but creates a greater challenge in the interpretation of the data as the number of attributes/minerals in the database controls its dimensionality. Consequently, a detailed description implies in higher data dimensionality.

In an effort to deal with this 'excess' of information we created a combination of the original attributes (represented in the parallel coordinates labeled Expanded Attributes in Figure 5) and the results from this combination is represented in the parallel coordinate named Collapsed Attributes (Figure 5). The combination is simple: it is the sum of the percentage of the attributes that represent the same mineral for each sample. Figure 5 provides an example for the mineral Biotite. In the original description, Biotite occurs in three different ways: Biotite as monomineralic grain, Biotite as monomineralic grain deformed and Biotite in plutonic rock fragment (Expanded Attributes). The combination of these attributes results in the more general attribute Biotite (Collapsed Attributes).

The analysis of the petrofacies is going to be carried through an association between the interaction of the analyst over this display and his/her experience and knowledge about the geology of the region of the database. The qualitative analysis of the cluster can also be obtained automatically by applying a statistical method over a selected cluster as exemplified in Figure 6 for a cluster of Well 2. The two available methods are Variance and Quartile. The method to be applied is a user's choice, in conjunction with knowledge about the database, in order to determine if the results make geologic sense.

Whenever the user is selecting a method he/she should remember that the calculations related to that are going to be applied over the samples of the selected cluster and the axes are going to be reordered. The results of this reordering will present which attributes/minerals/axes had more importance for the classification of the samples of one cluster for a particular well. The importance of the data decreases as you move towards the right. The result of the Quartile and the Variance analysis for one cluster of Well 2 can be seen in Figures 6a and 6b, respectively. In Figure 6a it is possible to see that the more important attributes found by applying Quartile method over this specific cluster are Mud Intraclast, Detrital Quartz, Calcite and Clay pseudo-matrix. These samples from this cluster do not have good characteristics because of the high values presented by the attributes and the known influence of them over the porosity of the rock. In Figure $6 \mathrm{~b}$ the results from the application of the Variance calculation are shown. For these clusters, the provided results do not show the most important attributes as the first attributes presented in the reordering of the axes are not present in these samples. Therefore, the Quartile showed more efficient results and this fact repeated throughout the analysis. For that reason, Quartile was the chosen method to perform the following analysis.

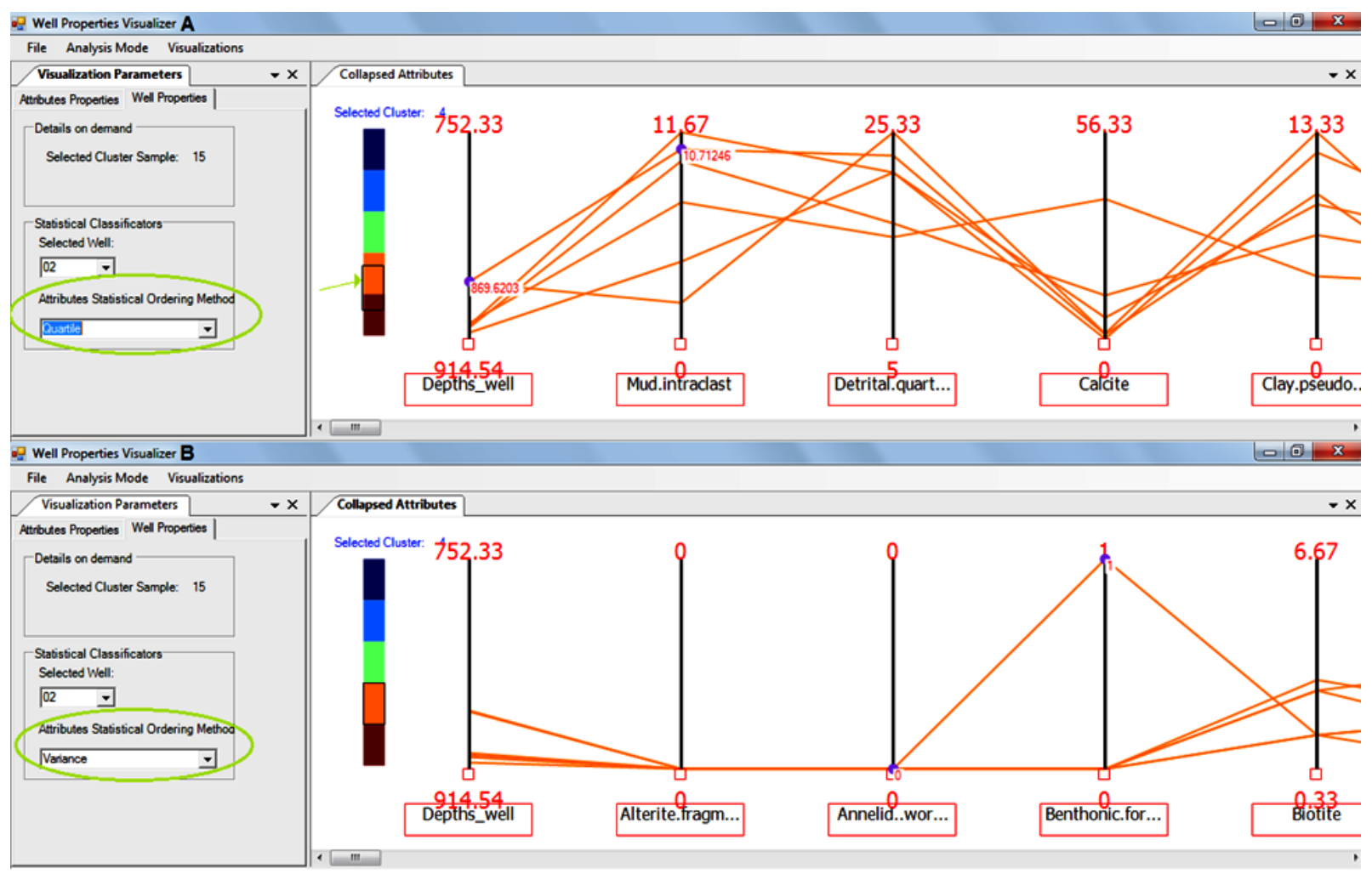

Fig. 6 - Representation of the application of Quartile (A) or Variance (B) method over the orange cluster of Well 2.

This procedure also allows the user to identify samples that seem to be different from others in the same cluster. Figure 7 shows the analysis for the Well 2 - Cluster 2. In the results for the comparison between PAM and AGNES, this was the only 
cluster that presented an issue in the classification for this well. Applying Quartile method over this cluster exposes one of the samples as having a different behavior when compared to the remaining wells. Using filtering and "pointer on the sample" the different behavior becomes clear and the sample is identified as being Well-02_20, the same sample that was 'misclassified' before.

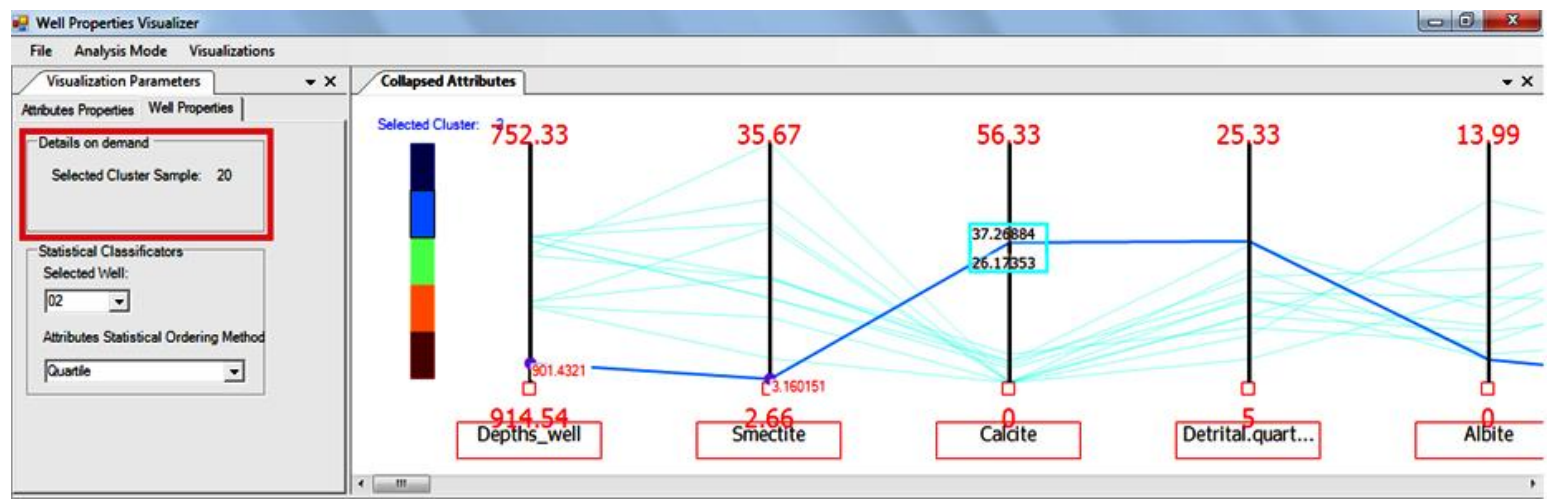

Fig. 7 - Parallel coordinates for Well_2 representing the "problematic" classification of the sample Well-2_20.

The good structure and classification obtained from PAM and AGNES for Well 10 can be identified in Figure 8 for each one of the clusters found in the PAM results.

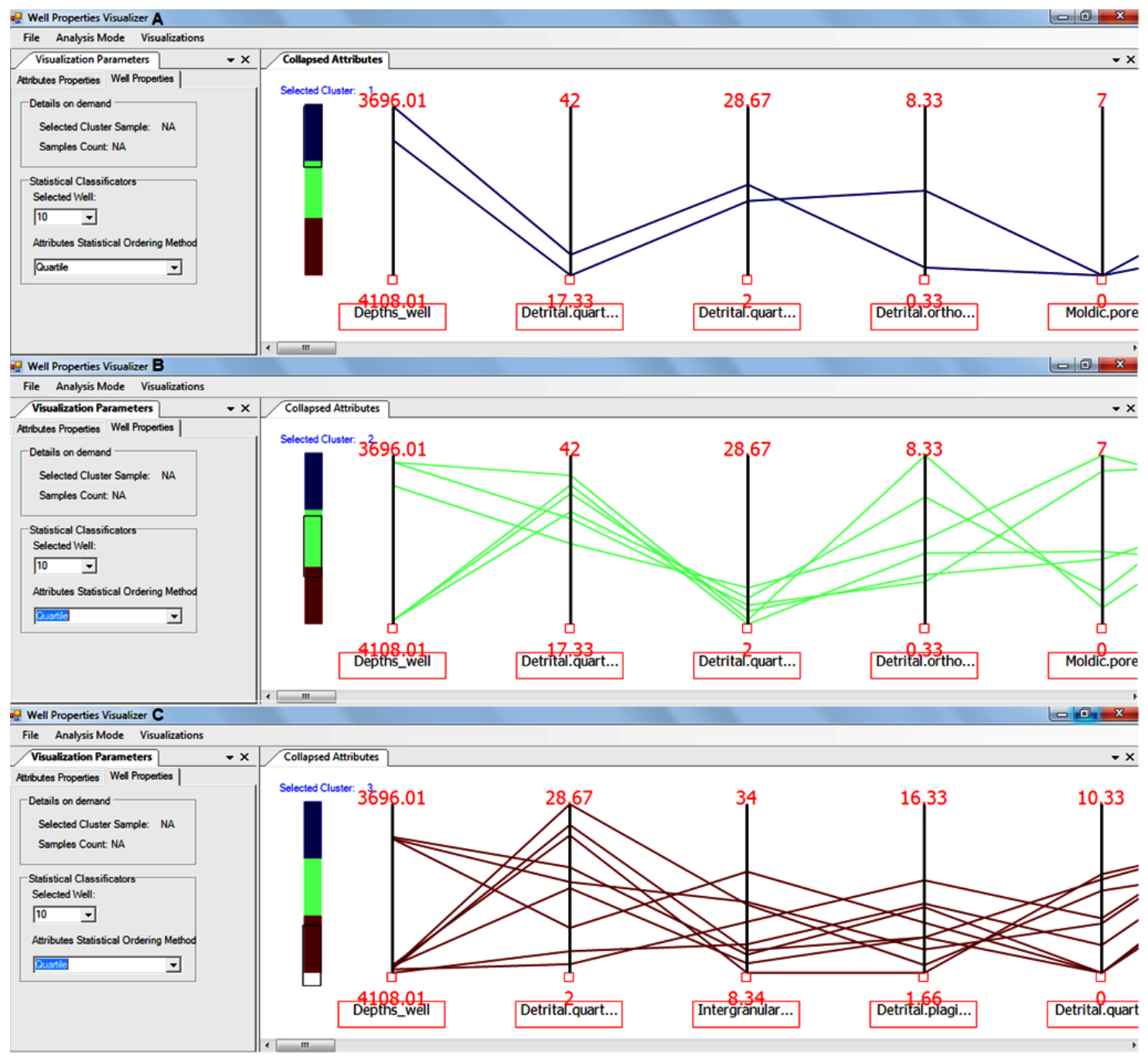

Fig. 8 - Statistical analysis of each one of the clusters classified for Well 10 in the first part of the methodology (PAM's results). 


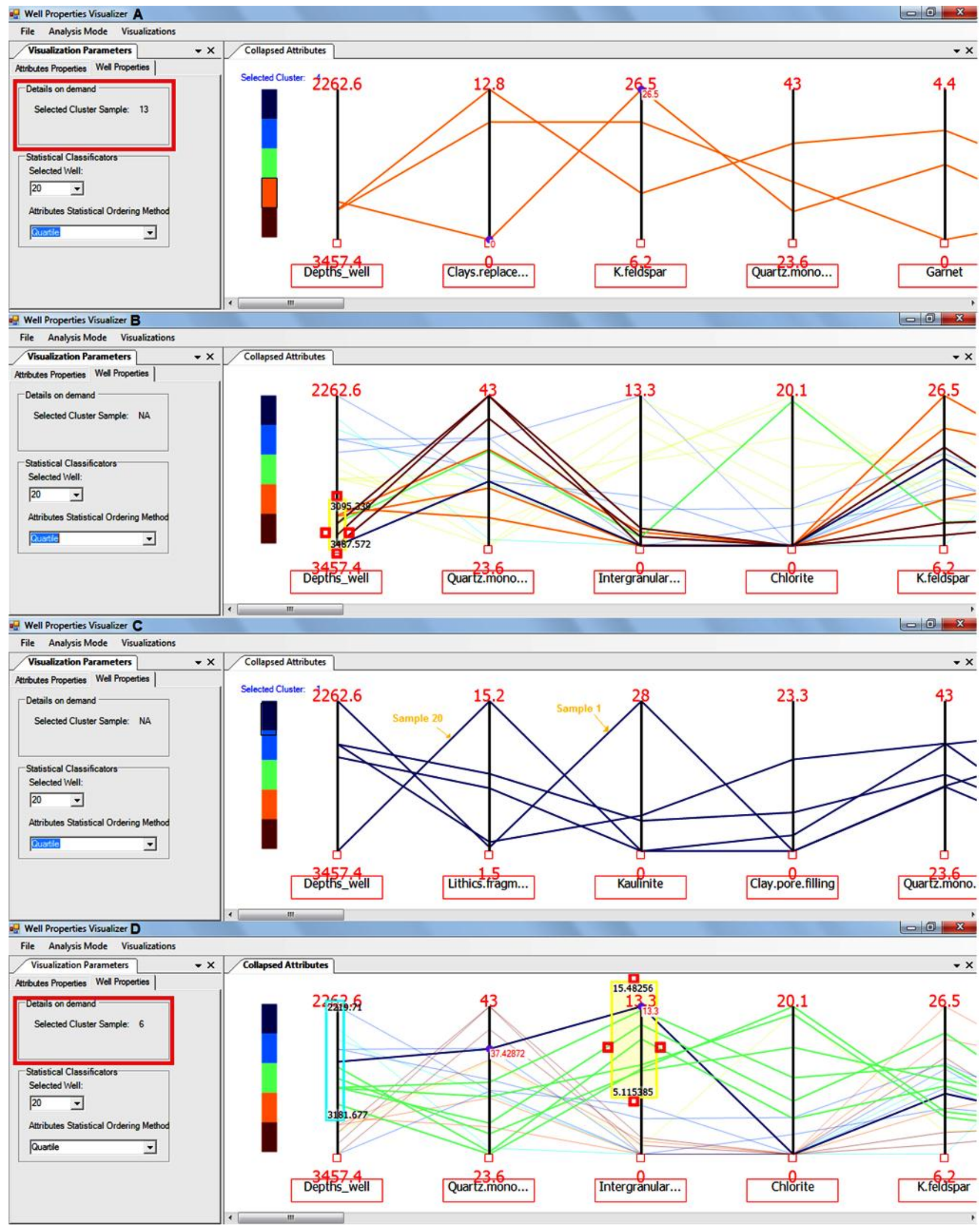

Fig. 9 - Parallel coordinates for Well 20. A) Highlight of the differences between sample Well-20_13 and the remaining samples of the cluster. B) Similarities between the samples from the clusters brown and orange. C) Highlight of the differences between Well20_1, Well-20_20 and the remaining samples of the cluster. D) Similarities between Well_20-6 and the cluster light green (cluster dark blue for the PAM results). 
The problems identified for Well 20 in the PAM and AGNES methods are highlighted and clearly exhibited in Figure 9. Figure 9a shows the cluster that contains the samples Well_20-13, Well_20-14 and Well_20-15. By filtering the sample Well 20-13 in the results for the Quartile method it is possible to see that this sample presents some different values when compared to the other samples of the cluster for the most important attributes of the data. Figure 9b demonstrates the similarities between the clusters brown and orange by applying filtering and Quartile method over all the samples of the well. This confirms the results obtained from AGNES (Figure 2f) and the relative proximity of the pink and light blue clusters in the PAM results (Figure 1 - Well 20). Figure 9c displays samples Well -20_20 and Well-20_1 as having different values for the order of the attributes obtained from the Quartile method over this cluster. This also confirms the different branches shown in the AGNES method (Figure 2f) and the spread shape of the samples shown in the PAM method (Figure 1). Finally, Figure 9d expresses the similarities between the sample Well 20-6 and the cluster light green, confirming the results for the AGNES method (Figures 2e and 2f) regarding the dark blue cluster found in the PAM results (Figure 1 - Well 20). The decision about the classification of these 'problematic' samples is going to be made by the analyst, based on his/her knowledge of the data.

\section{Conclusions}

We presented a methodology to analyze petrographic tables to obtain the petrofacies of the data. This methodology facilitates the analyst to gain insights about the whole database using a faster method when compared with analysis using the manual method. It also allows the validation of the results, being a powerful tool to qualitatively and quantitatively assist the analyst in the identification, interpretation of heterogeneities and validation of petrofacies.

The results from the first part of the methodology demonstrate that combing PAM with silhouette analysis is a valuable method for determining the number of petrofacies in each well. They cannot be taken as final results and need to be carefully analyzed in accordance with the geologic information available. AGNES does provide good insights about the similarities between the samples, but it does not have a final number of clusters for the analyzed database as PAM does. It is a method to use for comparison and cannot be used alone.

It is worthy to remember that both methods have some limitations. The PAM is limited to small databases (wells with less than 100 thin-sections each) and works effectively with data that contains a maximum of 5 clusters. The main limitation of the AGNES is that it does not change an object (sample) of a cluster after it has been linked. This can be interpreted to mean that the order of the samples could have a big impact on the final results. For this work these are not big limitations insomuch as it is hard to find databases with more than 100 thin-sections for each well, the number of petrofacies for the well is not large either, and the results for AGNES are not used on their own.

From the second part of the tool it is possible to conclude that the application we developed provides a more refined analysis of the cluster/petrofacies allowing the user to: (1) interact with the data; (2) find the minerals that might have influenced in a specific cluster formation; and (3) find out readily the range of values that each mineral has for the entire basin, for each well and even for a selected cluster. The features implemented in this analysis break the limitations of the parallel coordinates regarding the dimensionality of the data.

The geological results depend on the knowledge of the analyst about the data because the statistics can be right but there is no meaning for the Geology or vice-versa. The tool allows the analyst to gain insights about individual wells but does not allow a valuable inter-well analysis, and we intend to deal with this challenge in future work.

The Aitchison's methodology was not applied to any portion of the tool because it has some limitations related to the database. The most important being the logarithmic calculations as a base for all operations and the databases from petrographic analysis contain a considerable number of zero-values. Some works were developed to deal with this problem, but the use of them in our database is intended to be future work.

Overall, the methodology can help in the analysis of the distribution of the diagenetic constituents, which have a direct impact in the determination of the quality of the reservoirs and can optimize the data analysis of similar databases, accelerating the analysis and reducing the committed work by the experts.

\section{Acknowledgements}

We would like to thank ENDEEPER - Rock Knowledge Systems for providing the data used in this article. We also thank Jamie McInnis for her suggestions and reviews. This research was supported in part by the Science without Borders program from the National Council for Scientific and Technological Development (CNPq), Brazil; by the Federal University of Juiz de Fora; and by the NSERC / Alberta Innovates Technology Futures (AITF) / Foundation CMG Industrial Research Chair program in Scalable Reservoir Visualization at the University of Calgary. 


\section{References}

Asmus, H. E., Porto, R. 1980. Differences in the early stages of the evolution of the Brazilian continental margin: possible causes and implications. (Diferenças nos estágios iniciais da evolução da margem continental brasileira: possíveis causas e implicações), trans J. T. Cevolani. In: SBG, Congresso Brasileiro de Geologia 31: 225-239.

Aitchison, J. 1986. The Statistical Analysis of Compositional Data. New York: Chapman \& Hall.

Al-Anazi, A., Gates, I. D. 2010. On the Capability of Support Vector Machines to Classify Lithology from Well Logs. Natural Resources Research 19 (2): 125-139. http://dx.doi.org/10.1007/s11053-010-9118-9.

van der Boogaart, K. G., Tolosana, R. 2005. The composition Package. http://cran.r-project.org (accessed 15 September 2012).

Bosch, M., Zamora, M., Utama, W. 2002. Lithology Discrimination from Physical Rock Properties. Geophysics 67 (2): $573-581$. http://dx.doi.org/10.1190/1.1468618.

Bren, M., Batagelj, V. 2003. Compositional data analysis with R. In: Proceedings CoDaWork'03, Girona, Spain, 111-122.

Bren, M., and Batagelj, V. 2006. Visualization of three- and four-part (sub)compositions with R. In: Buccianti, A., Mateu-Figueras, G., and Pawlowsky-Glahn, V. (eds) Compositional Data Analysis in the Geosciences: From Theory to Practice. Geological Society, London, Special Publications, 264: 129-143.

Buccianti, A., Mateu-Figueras, G., and Pawlowsky-Glahn, V. (eds) 2006. Compositional Data Analysis in the Geosciences: From Theory to Practice. Geological Society, London, Special Publications, 264.

Cevolani, J. T., Oliveira, L. C., Fonseca et al. 2011. Visualization and Automatic Classification of Sedimentar Petrofacies. (Visualização e Classificação Automática de Petrofácies Sedimentares), trans J. T. Cevolani. In: 6th Brazilian Congresso f Research and Development in Petroleum and Gas - 6 PDPETRO, Florianópolis.

Chukwu, G. A. 1991. The Niger Delta Complex Basin: Stratigraphy, Structure and Hydrocarbon Potential. Journal of Petroleum Geology 14 (2): 211-220. http://dx.doi.org/10.1111/j.1747-5457.1991.tb00363.x.

Dubois, M. K., Bohling, G. C., Chakrabarti, S. 2006. Comparison of four approaches to a rock facies classification problem. Elsevier Ltd. Computer \& Geosciences 33 (2007): 599-617. http://dx.doi.org/10.1016/j.cageo.2006.08.011.

Highley, D. 2004. The Talara Basin Province of Northwestern Peru: Cretaceous-Tertiary Total Petroleum System. U. S. Geological Survey Bulletin 2206-A. http://pubs.usgs.gov/bul/2206/A (accessed in 1 October 2012).

Inselberg, A. 1985. The plane with parallel coordinates. The Visual Computer 1: 69-91.

Kaufman, L.; Rousseeuw, P. J. 2005. Finding Groups in Data: An introduction to Cluster Analysis. Second Edition. Wiley-Interscience United States of America. Chaps. 1-2, p. 1-126.

Küchle, J.; Holz, M. 2002. Application of the Sequence Stratigraphy for the Multiscale Characterization of the Reservoirs of the Guatá Group (Eo-permian of Paraná Basin) in the São Gabriel - RS region - Brazil (in Portuguese). Pesquisas em Geociências 29 (2): 3-20.

Lee, S. H., Datta-Gupta, A. 1999. Electrofacies Characterization and Permeability Predictions in Cardonate Reservoirs: Role of Multivariate Analysis and Nonparametric Regression. Paper SPE 56658 presented at the SPE Annual Technical Conference and Exhibition, Houston, Texas, 3-6 October. http://dx.doi.org/10.2118/56658-MS.

Ma, Y. Z. 2011. Lithofacies Clustering Using Principal Component Analysis and Neural Network: Applications to Wireline Logs. Math Geosci 43: 401-419. http://dx.doi.org/10.1007/s11004-011-9335-8.

Mukerji, T., Jorstad, A., Mavko, G., et al. 2001. Mapping lithofacies and pore-fluid probabilities in a North Sea reservoir: Seismic inversions and statistical rock physics. Geophysics 66 (4): 988-1001.

Oliveira, L. C. 2009. Study of the relationships among the stratigraphic framework and the diagenetic changes observed in the Devonian section of the Paraná Basin (Estudos das relações entre o arcabouço estratigráfico e as alterações diagenéticas observadas na seção Devoniana da Bacia do Paraná), trans. J. T. Cevolani. MS thesis. Rio de Janeiro, University of the Estate of Rio de Janeiro (February 2009)

R Development Core Team. 2009. R: A Language and Environment for Statistical Computing. R Foundation for Statistical Computing, Vienna, Austria. ISBN 3-900051-07-0.

Reynolds, J. H., Billheimer, D. 2002. Basic Compositional Data Analysis Functions for S+/R, http://www.biostat.wustl.edu/archives/html/s-news/2003-12/msg00139.html (acessed 2 October 2012). 
Silva, C. M. A. 1991. Diagenesis and Characterization of the Reservoirs of the Sandstones and Conglomerates of the Mucuri Member, Mariricu Formation (Early Cretaceous) - Espírito Santo and Mucuri Basins (Diagênese e Características de Reservatório dos Arenitos e Conglomerados do Membro Mucuri, Formação Mariricu (Cretáceo Inferior) - Bacias do Espírito Santo e Mucuri), trans. J. T. Cevolani. MS thesis. Ouro Preto, Federal University of Ouro Preto (November, 1991).

Thió-Henestrosa, S., Martín-Fernández, J. A. 2006. Detailed guide to CoDaPack: a freeware compositional software. In: Buccianti, A., Mateu-Figueras, G., and Pawlowsky-Glahn, V. (eds) Compositional Data Analysis in the Geosciences: From Theory to Practice. Geological Society, London, Special Publications, 264: 101-118.

Vendramin, L., Campello, R. J. G. B., and Hruschka, E. R. 2010. Relative Clustering Validity criteria: A Comparative Overview. Wiley InterScience. http://dx.doi.org/10.1002/sam.10080.

Zálan, P. V., Wollf, S., Conceição, J. C. J., et al. 1990. Parana Basin (Bacia do Paraná) trans J. T. Cevolani. In: Raja Gabaglia, G.P. and Milani, E. J. (eds) Origem e Evolução de Bacias Sedimentares. Rio de Janeiro. Petrobras/SEREC/CEM-SUD: 135-16 


\section{Appendix A - Silhouette Analysis}

\begin{tabular}{|ccccc|}
\hline \multicolumn{5}{|c}{ TABELA 1 - SILHOUETTE ANALYSIS RESULTS FOR ALL WELLS OF THE } \\
\hline & \multicolumn{2}{c}{ DATABASES } & $\underline{3}$ & \multicolumn{1}{c|}{} \\
\hline № of clusters & & & & \\
Talara Basin & & & & \\
SC - Well 1 & 0.21 & 0.23 & 0.17 & 0.16 \\
SC - Well 2 & 0.17 & 0.26 & 0.23 & 0.27 \\
SC - Well 3 & 0.21 & 0.24 & 0.07 & 0.09 \\
& & & & \\
Niger Delta Basin & & & & \\
SC - Well 5 & 0.24 & 0.2 & 0.25 & 0.27 \\
SC - Well 6 & 0.4 & 0 & 0 & 0 \\
SC - Well 7 & 0.21 & 0.19 & 0.18 & 0.18 \\
SC - Well 8 & 0.54 & 0.33 & 0.29 & 0.32 \\
SC - Well 9 & 0.34 & 0.34 & 0.35 & 0.34 \\
SC - Well 10 & 0.41 & 0.44 & 0.41 & 0.33 \\
& & & & \\
Espirito Santo Basin & & & & \\
SC - Well 11 & 0.34 & 0.26 & 0.26 & 0.14 \\
SC - Well 13 & 0.38 & 0.41 & 0.31 & 0.23 \\
SC - Well 14 & 0.17 & 0.2 & 0.15 & 0.17 \\
SC - Well 15 & 0.23 & 0.16 & 0.09 & 0.16 \\
SC - Well 16 & 0.42 & 0.36 & 0.14 & 0.1 \\
SC - Well 17 & 0.35 & 0.34 & 0.29 & 0.28 \\
SC - Well 18 & 0.25 & 0.22 & 0.16 & 0.12 \\
SC - Well 19 & 0.07 & 0.12 & 0.13 & 0.1 \\
SC - Well 20 & 0.17 & 0.15 & 0.22 & 0.25 \\
SC - Well 21 & 0.34 & 0 & 0 & 0 \\
SC - Well 22 & 0.13 & 0 & 0 & 0 \\
SC - Well 24 & 0.18 & 0.22 & 0.16 & 0 \\
SC - Well 25 & 0.33 & 0 & 0 & 0 \\
SC - Well 26 & 0.46 & 0 & 0 & 0 \\
SC - Well 30 & 0.21 & 0 & 0 & 0 \\
\hline
\end{tabular}




\section{Appendix B - PAM's results for the remaining wells}
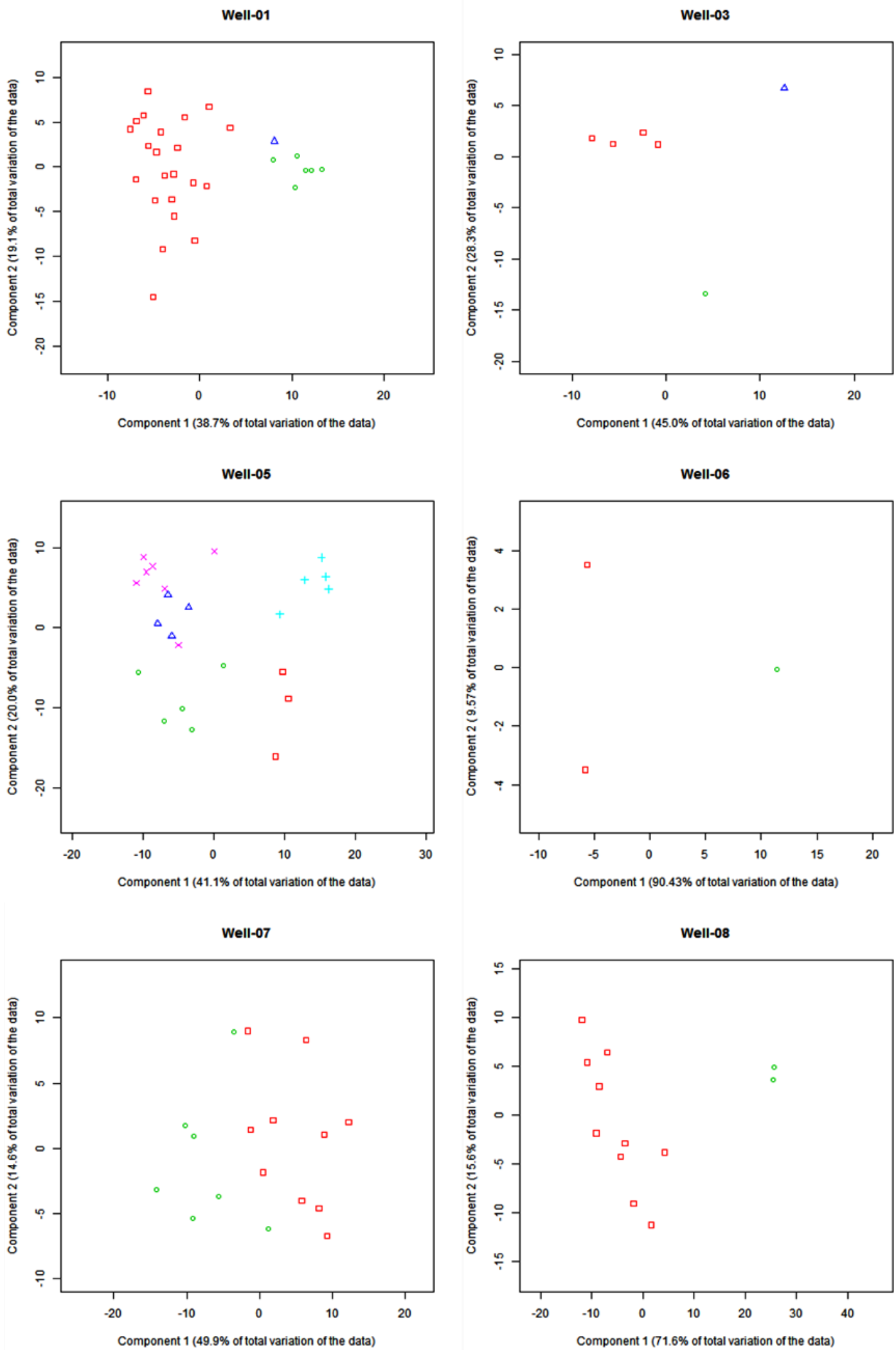

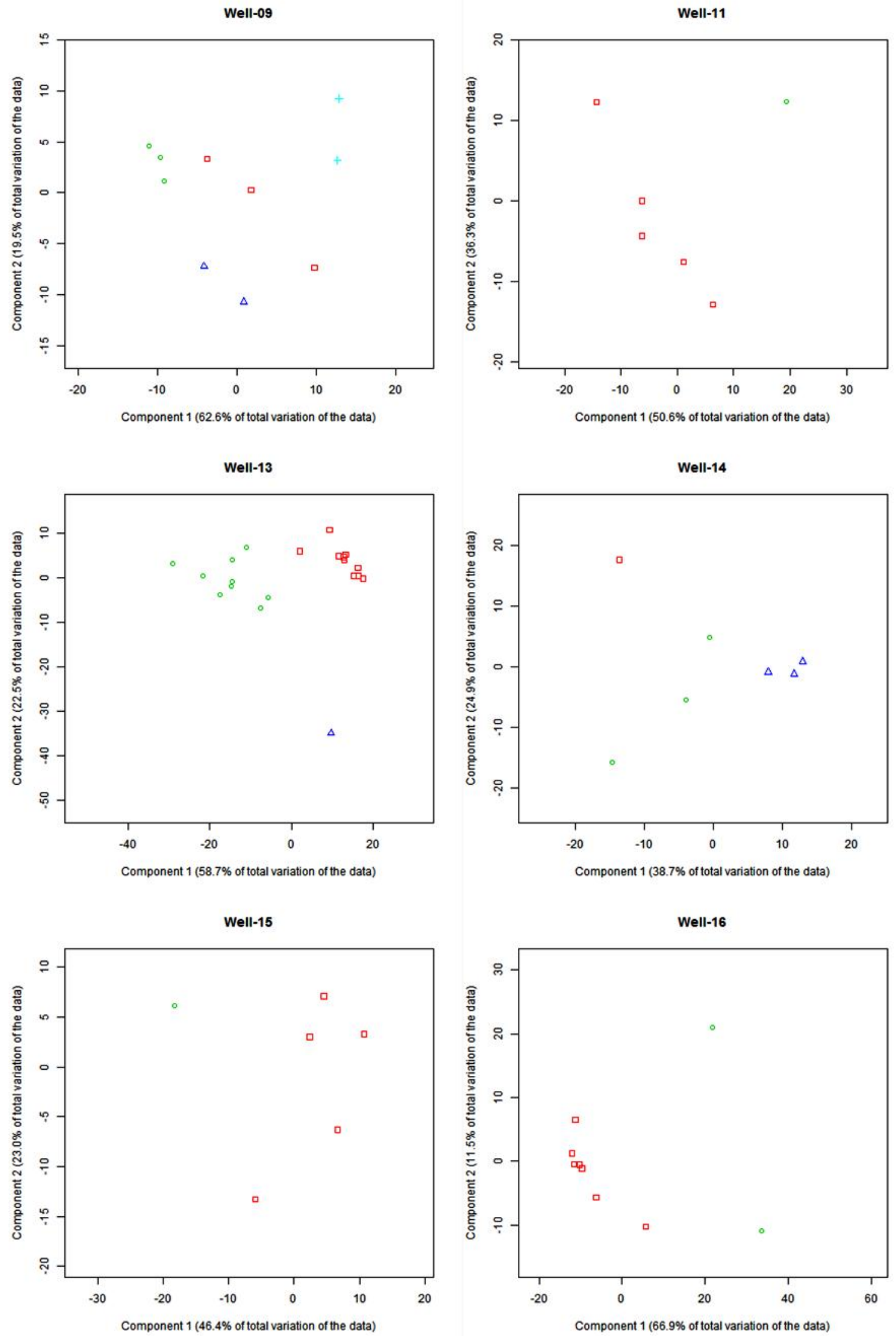

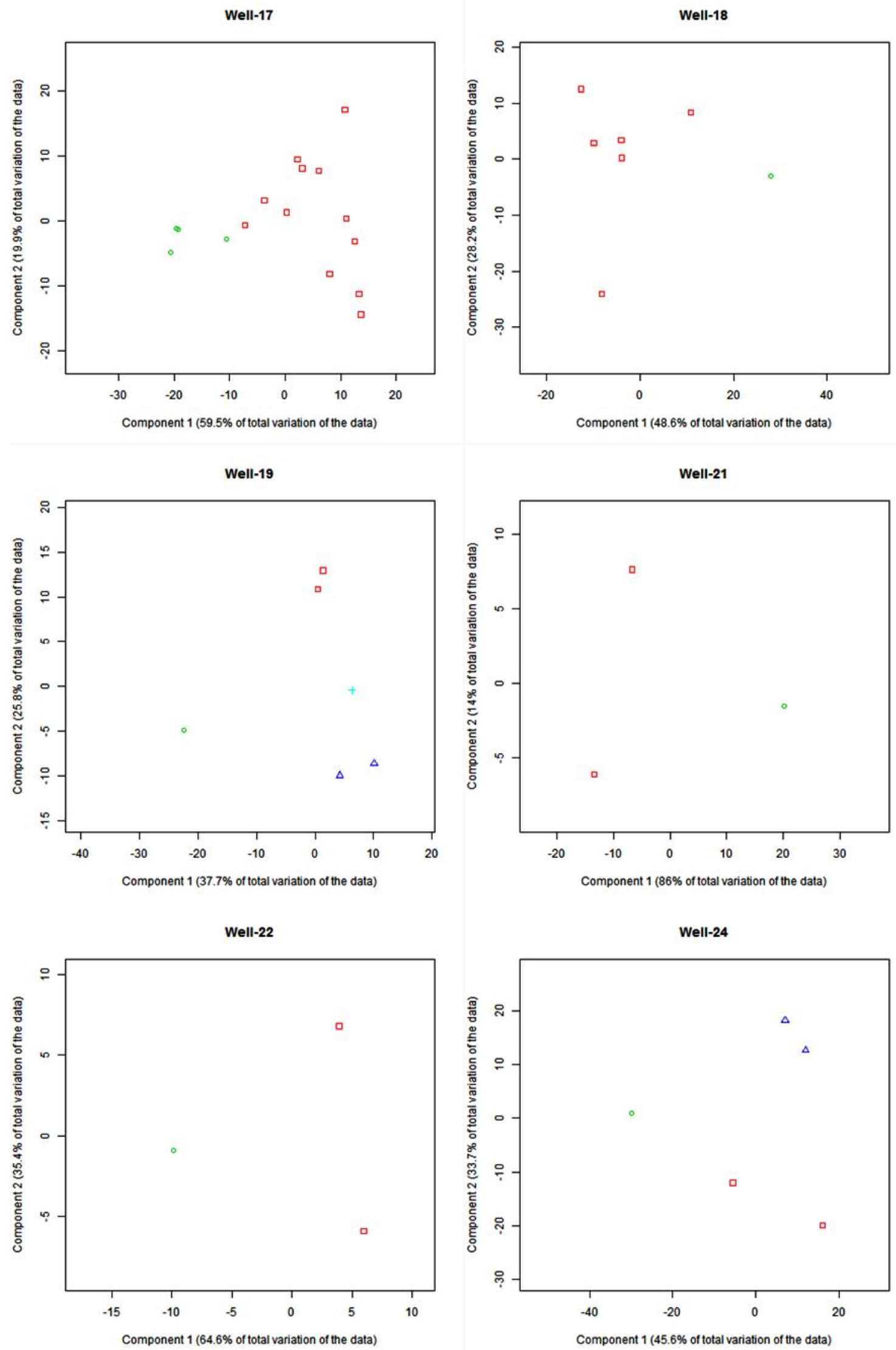

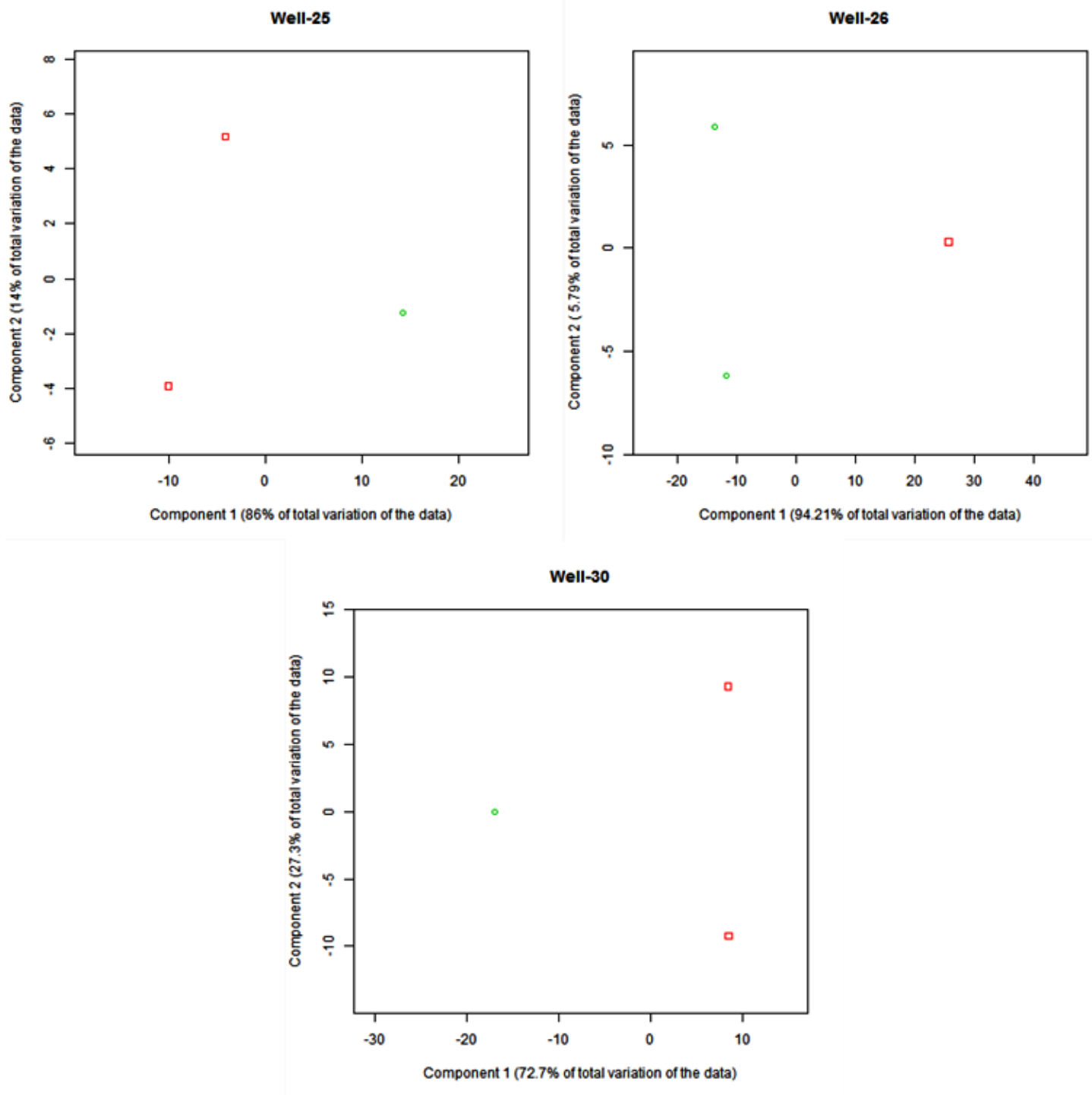
Appendix C - AGNES' results for the remaining wells
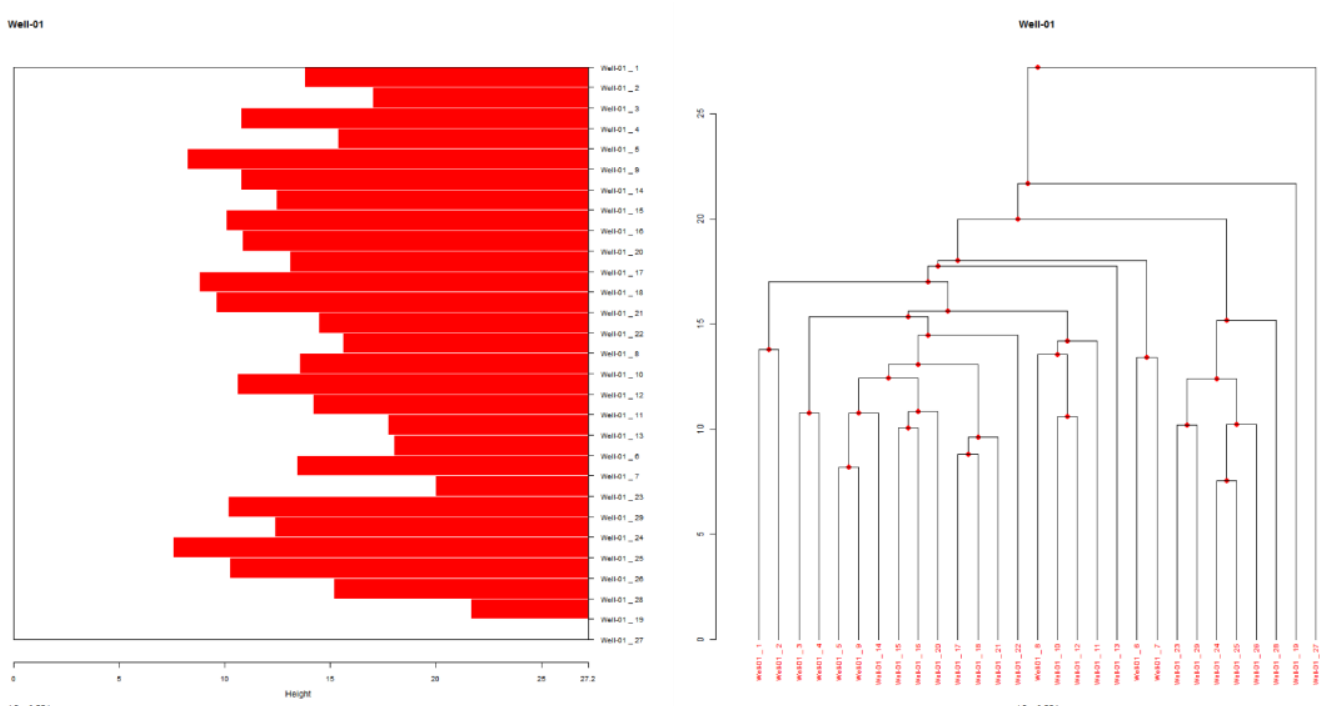

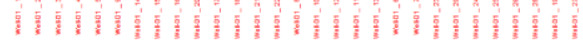

$x=0.5$,

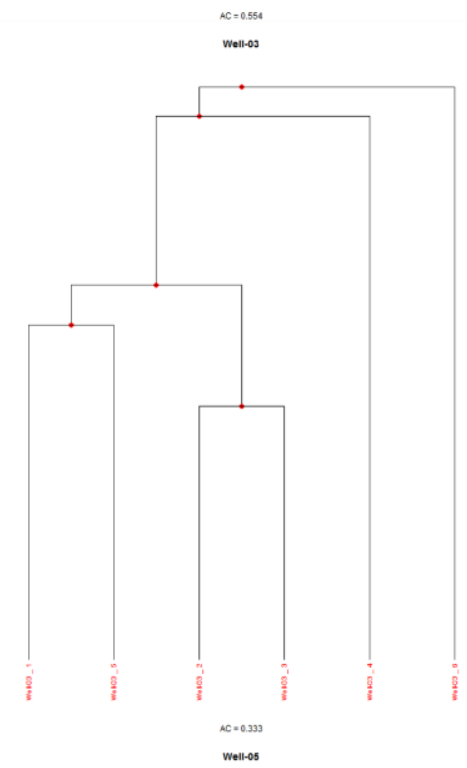

well-06
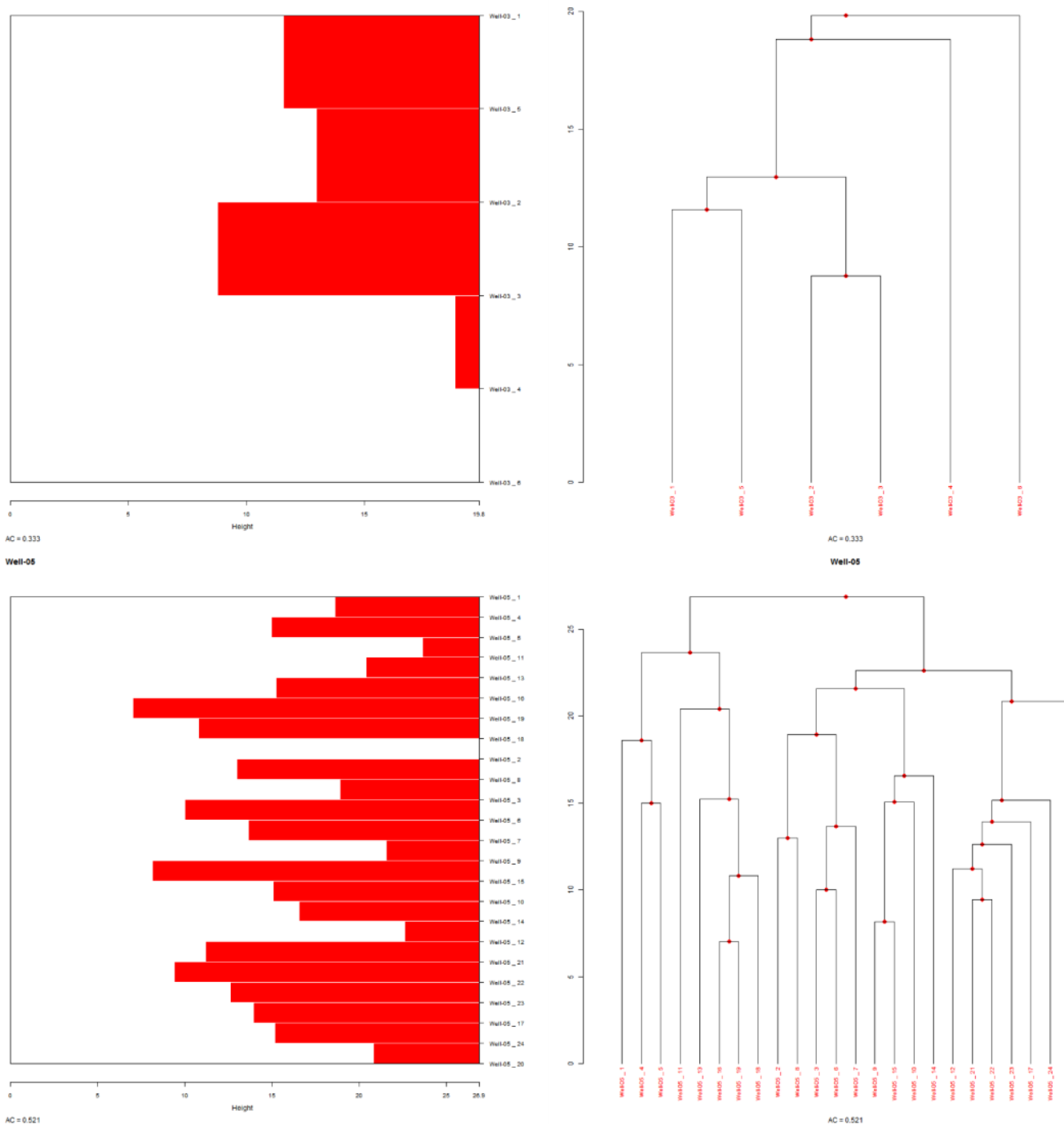


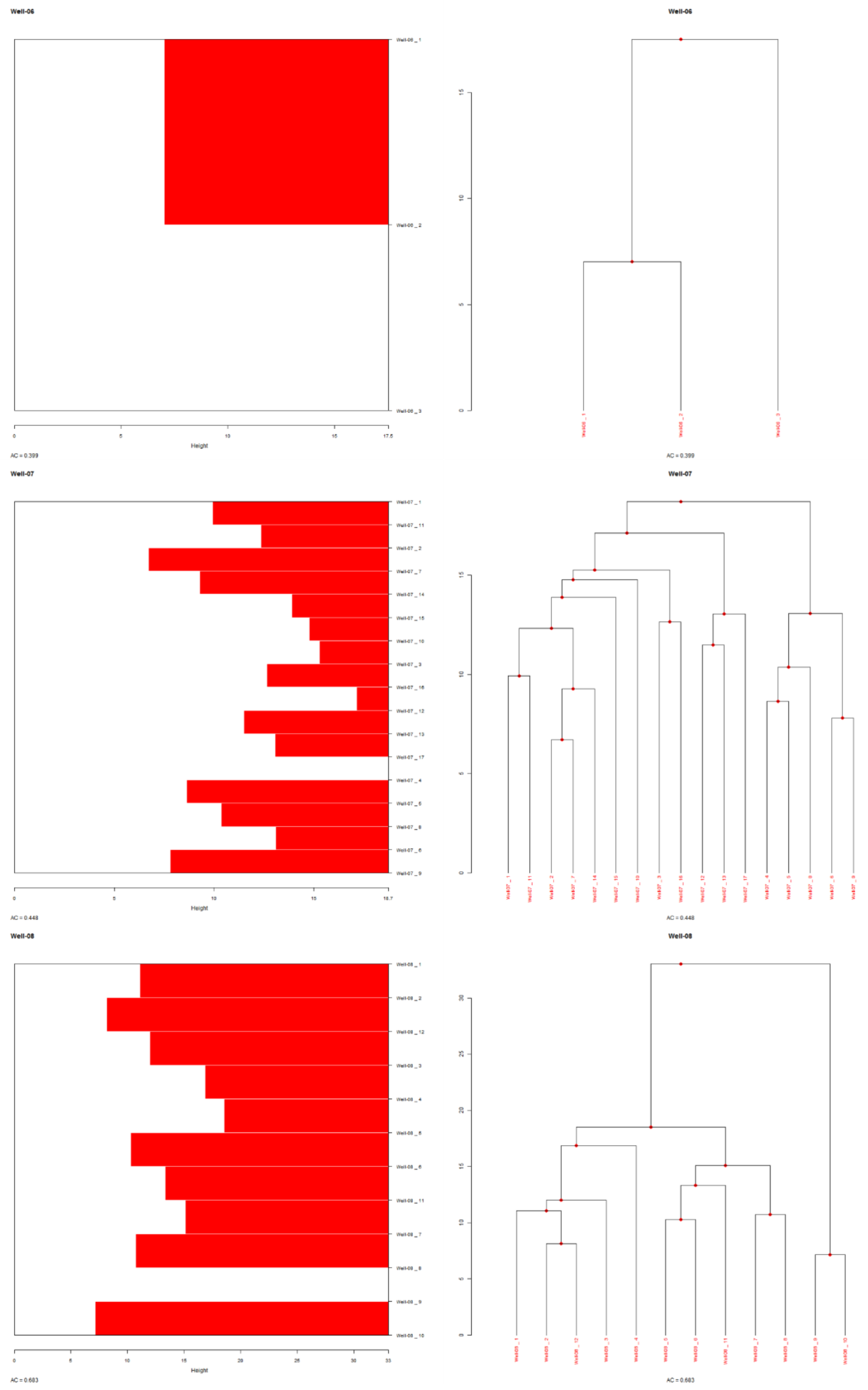



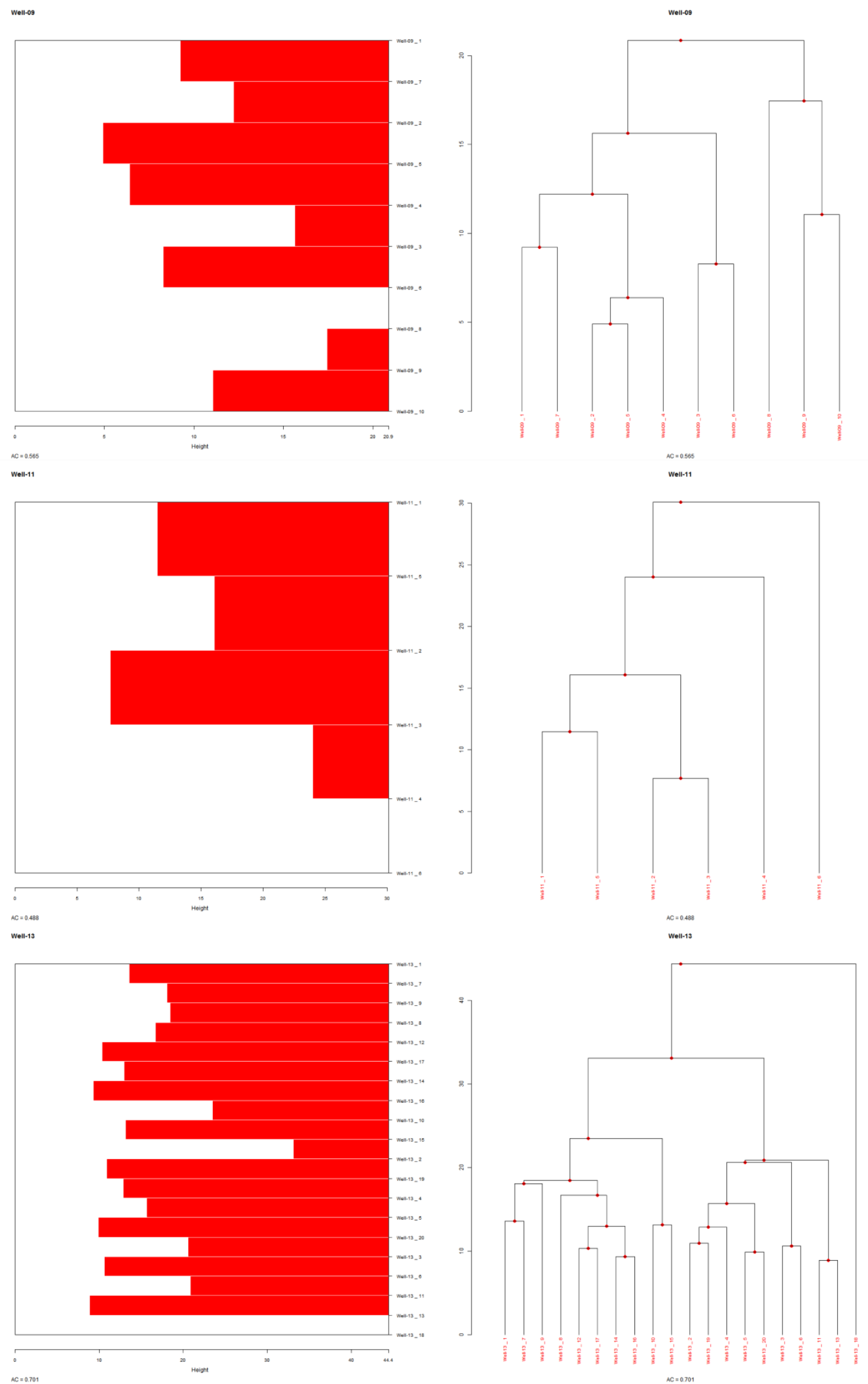


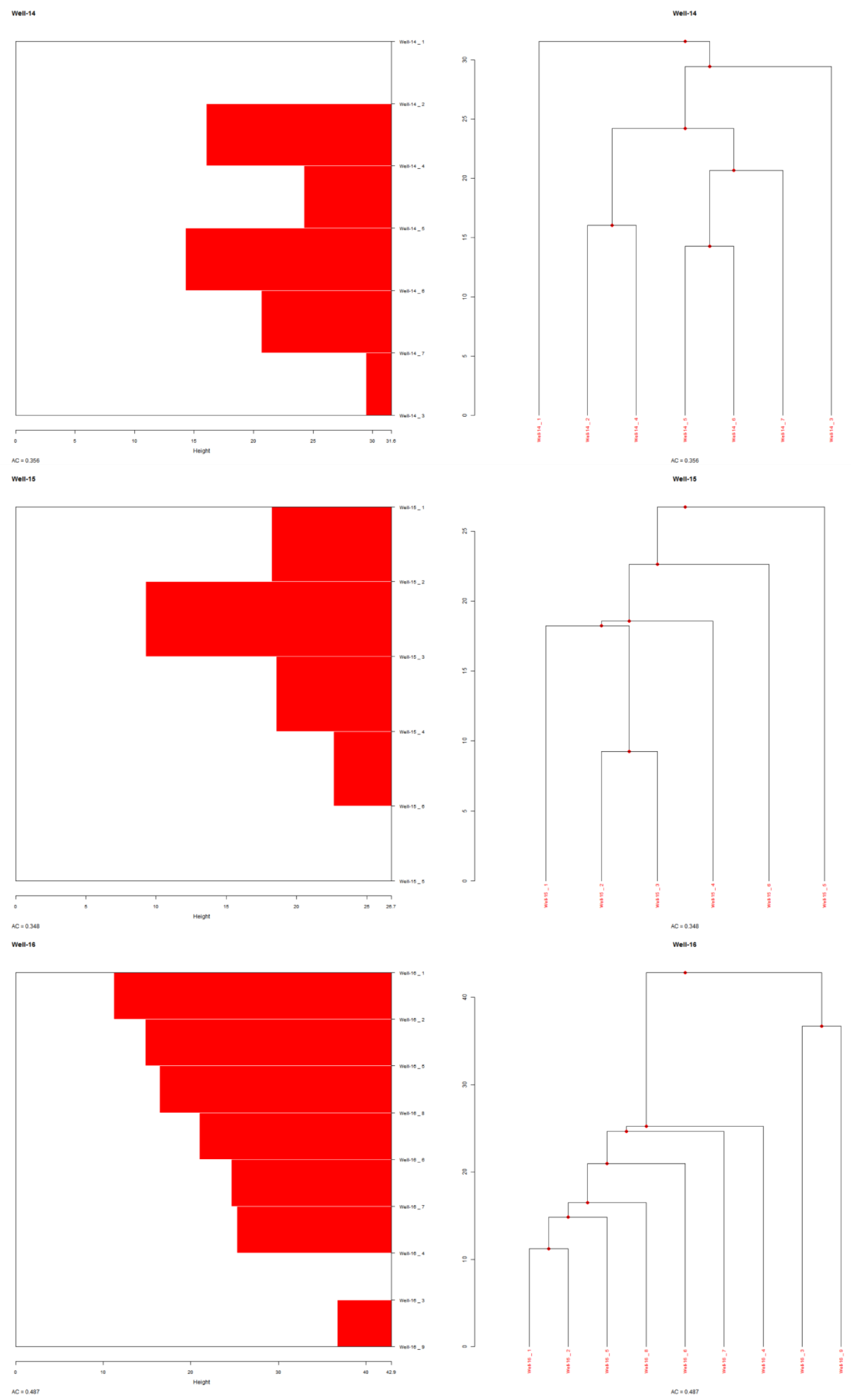




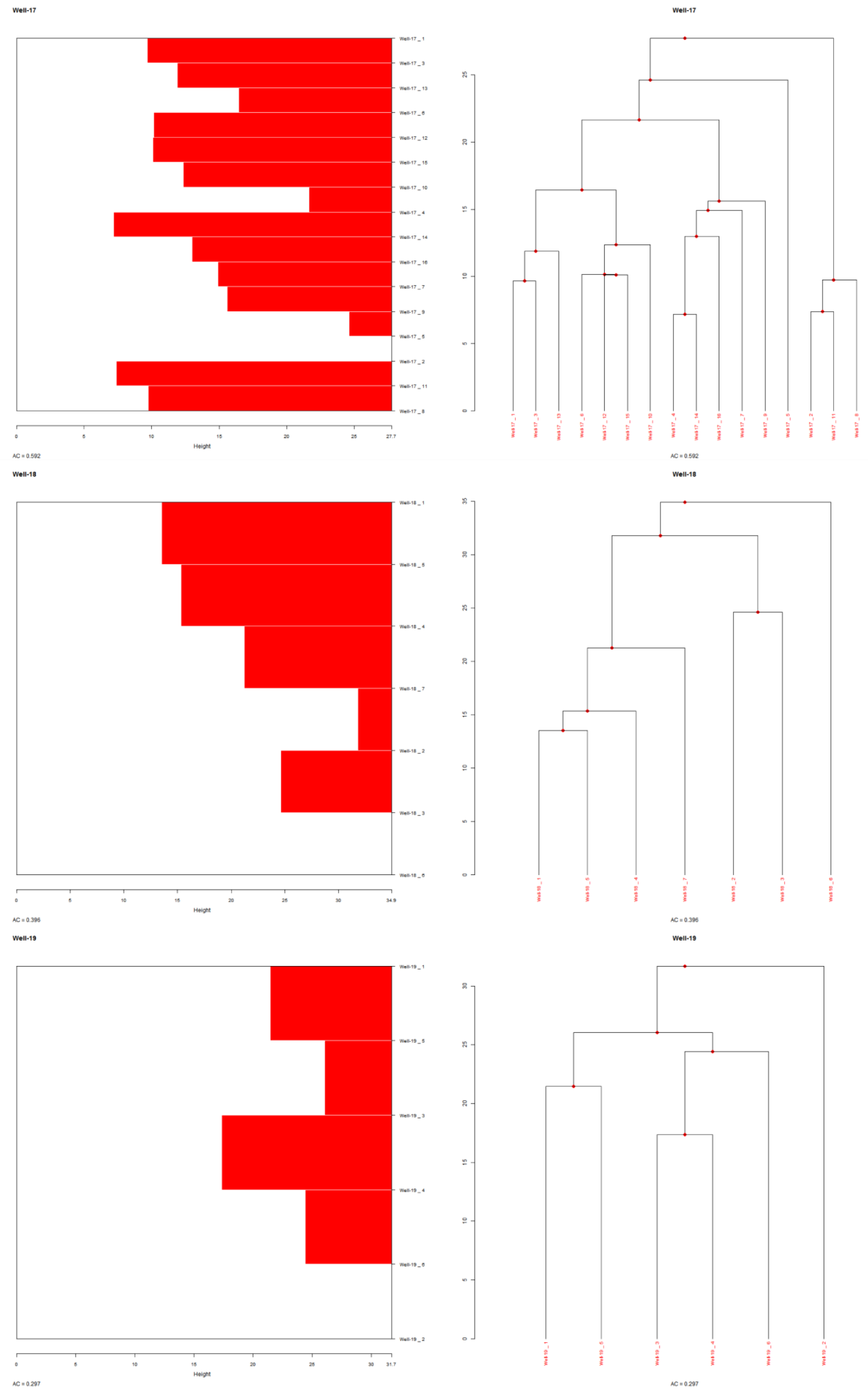




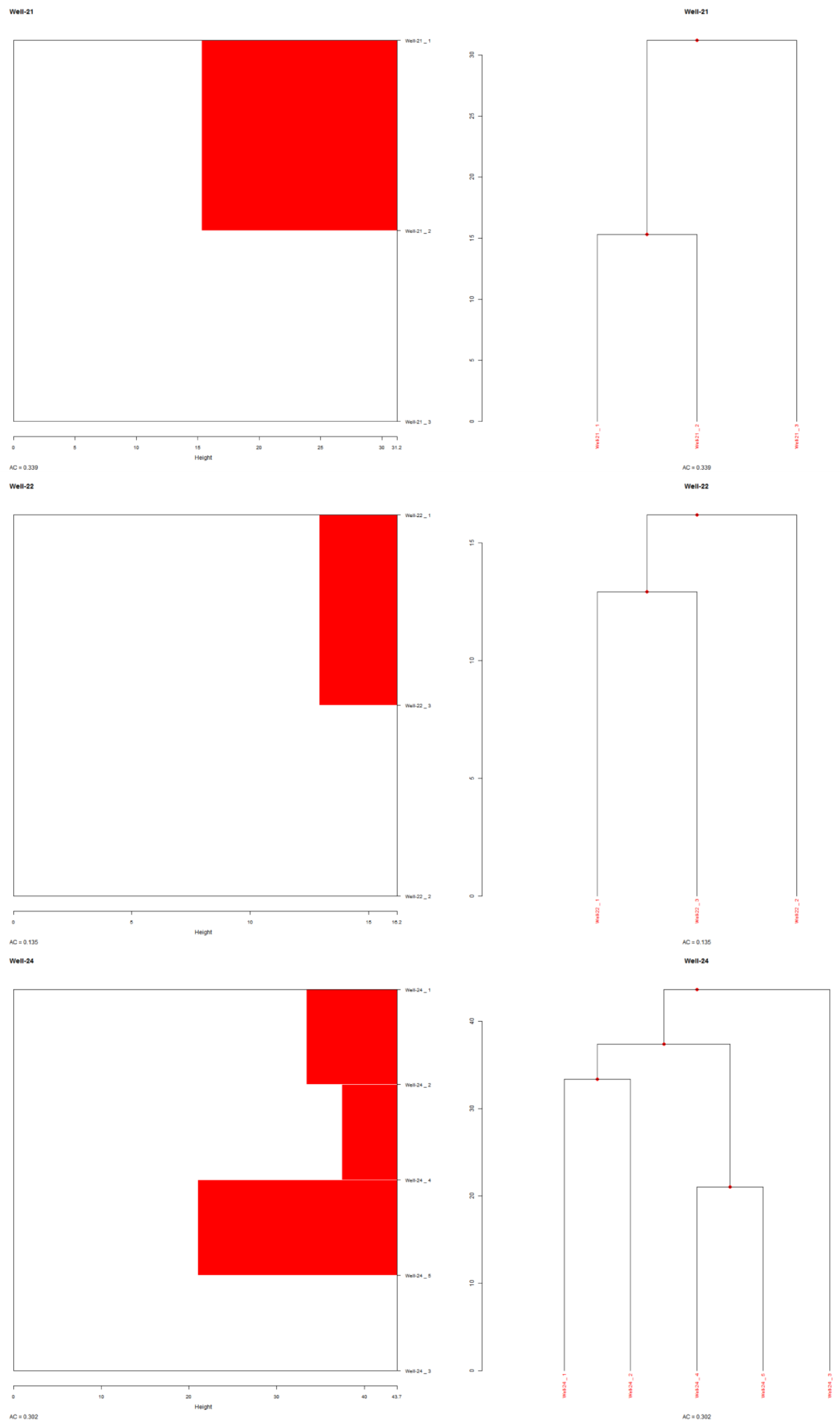



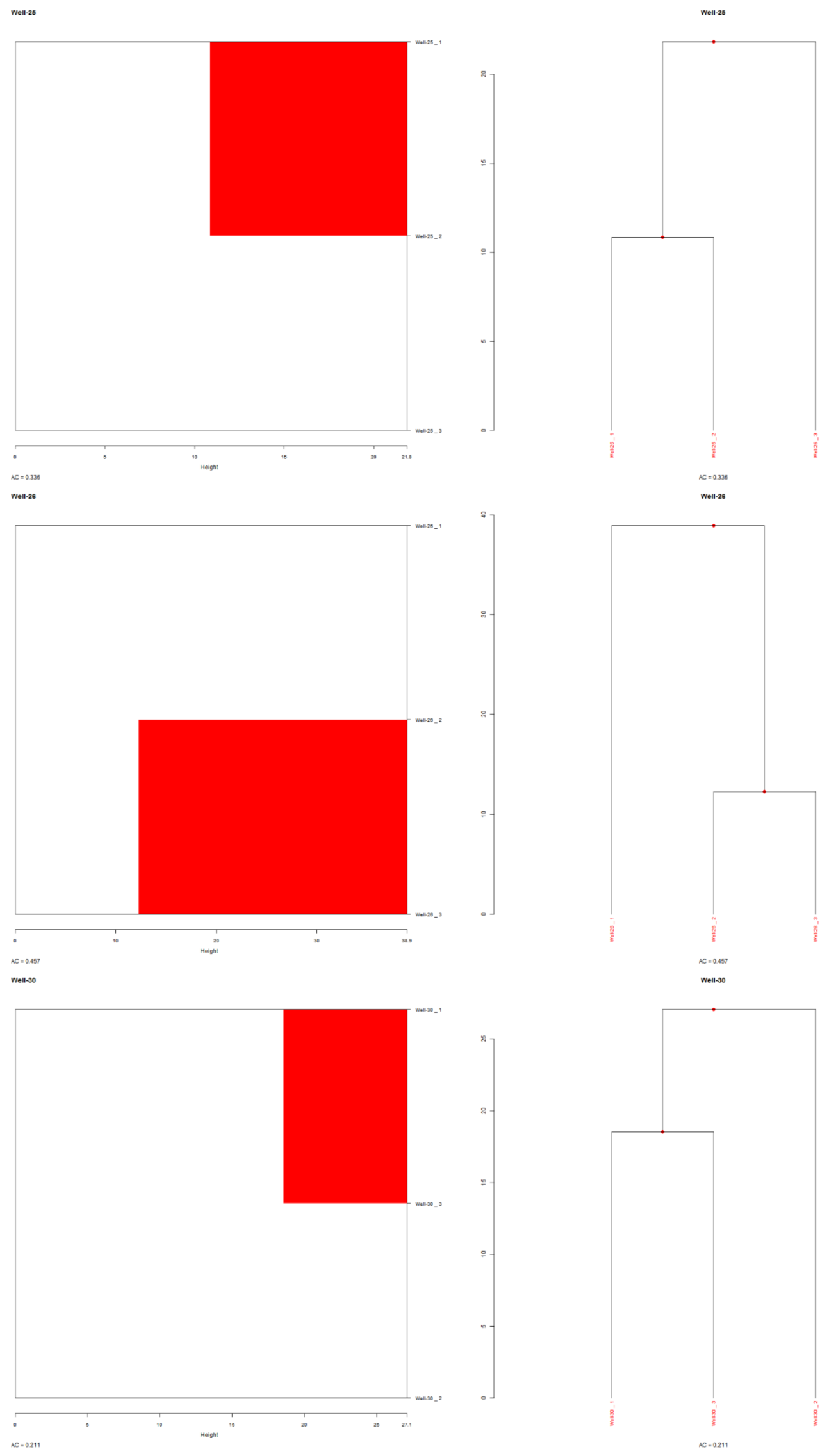